\title{
Über thermostabile bakterizide Stoffe des Blutserums.
}

\author{
Von \\ Yoshijiro Ikegami. \\ (池上芳次郎) \\ (Aus Prof. T. Kumagais medizinischer Klinik der. \\ Tohoku Tniversität zu Sendai.)
}

Schon früher wurde es von zahlreichen Autoren bestätigt, dass verschiedene Körperflüssigkeiten auf verschiedene Mikroorganismen abtötend wirken. Besonders wurde die bakterizide Fähigkeit des Blutes zuerst von Fodor $(1887)^{1)}$ und Nuttall (1888) ${ }^{2}$ nachgewiesen und die Bakterizidie des Blutserums zuerst von Behring (1888) und Buchner (1889). ${ }^{46}$ Buchner nannte diesen im normalen frischen Blutserum enthaltenen bakteriziden Stoff " Alexin" und, auf seine vergleichenden Versuche der bakteriziden Wirkung des Serums mit der des Exsudates gestützt, glaubte er, dass die Alexine aus den lebenden Leukozyten sezerniert werden könnten. Ha h $n, \bar{\gamma}$ der zuerst nur bei reinen Leukozyten, welche aus den Exsudaten gewonnen waren, die bakterizide Wirkung prüfte, nahm an, dass die Serumalexine und die bakteriziden Leukozytenstoffe ganz identisch wären. Schattenfroh ${ }^{s-11}$ fand, dass zwischen Alexinen und Leukozytenstoffen einige wichtige Verschiedenheiten vorhanden sind, trotzdem betrachtete er die Leukozytenstoffe als die Quelle der Alexine.

Seit der grundlegenden Arbeit Schattenfrohs beschäftigten sich zahlreiche Forscher ${ }^{12-6}$ mit diesen Leukozytenstoffen. Vor allem cntdeckte Pettersson, ${ }^{2-3}$ dass diese Leukozytenstoffe von Alexinen ganz verschieden sind, und auf Grund seincr Versuche nannte er diese Stoffe "Endolysin," weil diese Stoffe erst nach grosser Schädigung der Leukozyten aus diesen austreten und darin irgendwie dem Endoenzym ähnlich sind. Auch Schneide $\mathbf{r}^{4045}$ wies nach, dass diese beiden Stoffe ganz verschieden sind, aber im Gegensatz zu Pettersson dachte er, dass die Leukozytenstoffe von lebenden Leukozyten sezerniert werden, und, von diesem Gedanken 
ausgehend, nannte er diese Stoffe "Luukin." Kling ${ }^{4+3}$ untersuchte verschiedene Eigenschaften der Leukozytenstoffe und kam zu gleichen Resultaten wie Pettersson.

Über thermostabile bakterizide Serumstoffe berichteten schon Behring und $\mathrm{Nissen},{ }^{45}$ Bonaduce ${ }^{46}$ und Pirenne, ${ }^{47}$ und in neuerer Zeit wurden diese Serumstoffe noch eingehender von Dold, ${ }^{48)}$ Seiffert, ${ }^{\text {,9-51) }}$ Schou, ${ }^{52)}$ Selter ${ }^{53-54)}$ und Pettersson ${ }^{55)}$ untersucht, und infolgedessen zog dieses Thema die Aufmerksamkeit aller Welt auf sich. Über die Frage der Eigenschaften dieser Stoffe ist aber bisher nur wenig berichtet worden. Unsere nachfolgenden Versuche baziehen sich auf diesen Punkt.

\section{Methodik.}

Bevor wir auf unsere Versuche eingehen, müssen wir kurz die Methodik besprechen. $Z_{u}$ den Versuchen benutzten wir, neben Menschensera, Sera von Kaninchen, Meerschweinchen, Hunden, Hämmeln, Rindern, Pferden u. Schweinen. Das Blut wurde beim Menschen aus den Hautvenen der Ellenbenge, beim Kaninchen aus Ohrvenen, beim Meerschweinchen aus dem Herzen, beim Hunde aus Femoralisvenen und beim Hammel aus Jugularisvenen steril entnommen. Beim Rinde, Pferde und Schweine wurde das Blut beim Schlachten der Tiere möglichst steril aufgefangen. Das aus diesen Blute gewonnene frische Serum wurde in Mengen von $0,5 \mathrm{~cm}$ in schmale Reagenzröhrchen gefüllt und teils direkt, teils nach Inaktivierung durch meistenteils halbstündiges Erwärmen im Wasserbad bei $56^{\circ} \mathrm{C}$ zu Versuchen benutzt.

Als restbakterien wählten wir in der Regel Bac. Typhi aus, aber bei ganz besondcren Versuchen benutzten wir noch verschiedene andere Bakterienarten. Wir benutzten zur Prüfung immer die Bakterien von 24 stündiger Bouillonkultur im Brutschrank bei $37^{\circ} \mathrm{C}$.

Als Prüfungsmethode der bakteriziden Wirkung wurde die Buchner sche Plattenmethore gewählt, aber in Einzelheiten etwas verschieden ausgeführt. Wir gaben eine kleine $\ddot{O}_{\text {se }}$ aus einer Bouillonkultur von Testbakterien auf $5 \mathrm{~cm}$ Bouillon und beimpften hiervon eine kleine Öse voll in die zu prüfenden Serumröhrhen. Zur Kontrolle wurde 0,5 ccm Bouillon mit der gleichen Bikterienmenge beimpft. Sofort nach der Beim-

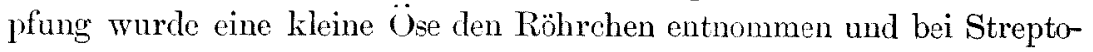
u. Pneumokokken besonders dem auf $50^{\circ} \mathrm{C}$ gelösten Blutagar und bei anderen Bakterienarten dem auf $50^{\circ} \mathrm{C}$ gelösten gewöhnlichen Nähragar beigemischt und in eine Petri sche Schale ausgegossen, und dann wurden 
alle Schalen in dem Brutschrank bei $37^{\circ} \mathrm{C} 24-48$ Stunden lang gelassen. Nach der Beimpfung kamen sämtliche Röhrchen in den Brutschrank bei $37^{\circ} \mathrm{C}$ und nach bestimmter Zeit, d.h. nach 4 oder 14 und 24 Stunden, wurde obiges Verfahren wiederholt. Darauf wurden die auf den Platten gewachsenen Kolonien gezählt, und nach der Kolonienzahl beurteilten wir die bakterizide Wirkung der Sera. Als Massstab der bakteriziden Wirkung bestimmten wir der Einfachbeit halber Folgendes: Wenn die Kolonienzahl nach 24 stündiger Bebrütung null oder weniger als diejenige der sofort nach der Bakterienbeimpfung ausgeführten Plattenkultur war, so sind diese Sera bakterizid ; wenn erstere Zahl höher als letztere ist, so sind die Sera entwicklungshemmend; wenn erstere reichlich (mehr als etwa Tausend) oder gar unzählbar ist, dann sind die Sera nicht bakterizid.

\section{Tabelle I.}

Menschenserum : aktiv und $\frac{1}{2}$ Stunde bei $56^{\circ} \mathrm{C}$ inaktiviert, $0,5 \mathrm{ccm}$ benutzt.

Aussaat: Bouillonkultur von Bac. Typhi.

\begin{tabular}{|c|c|c|c|c|c|c|c|}
\hline \multirow{3}{*}{$\begin{array}{c}\text { Menschen- } \\
\text { Nr. }\end{array}$} & \multirow{3}{*}{ Krankheitsname } & \multicolumn{6}{|c|}{ Kolonienzabl auf den Platten } \\
\hline & & \multicolumn{2}{|c|}{$\begin{array}{l}\text { sofort nach } \\
\text { Aussaat }\end{array}$} & \multicolumn{2}{|c|}{$\begin{array}{c}\text { nach } 4 \\
\text { Stunden }\end{array}$} & \multicolumn{2}{|c|}{$\begin{array}{l}\text { nach } 24 \\
\text { Stunden }\end{array}$} \\
\hline & & aktiv & $\begin{array}{l}\text { in } \\
\text { aktir }\end{array}$ & alitiv & $\begin{array}{l}\text { in- } \\
\text { aktiv }\end{array}$ & aktiv & $\begin{array}{l}\text { in- } \\
\text { aktiv }\end{array}$ \\
\hline 1 & Typhus abdominalis & is & 28 & 0 & 40 & 0 & 11 \\
\hline 2 & Typhusreconvalescenz & 2 & 23 & 0 & 28 & 0 & 3 \\
\hline 3 & Paratyphus B & - & 23 & - & 29 & - & 0 \\
\hline 4 & $\mathrm{do}$ & - & 46 & - & 48 & - & 3 \\
\hline 5 & Appendicitis & 1 & 0 & 0 & 3 & 0 & 0 \\
\hline 6 & do & - & 21 & - & 32 & - & 0 \\
\hline 7 & Dysenterie & - & 21 & - & 17 & - & 0 \\
\hline s & do & - & 38 & - & 32 & - & 1 \\
\hline 9 & Lungentuberculose & 10 & 8 & 0 & 41 & 0 & 3 \\
\hline 10 & do & - & 34 & - & 22 & - & 0 \\
\hline 11 & do & - & 46 & - & 77 & - & 0 \\
\hline 12 & Spitzenkatarrb & 1 & 12 & 7 & 84 & 0 & 2 \\
\hline 13 & do. & 3 & $\$ 1$ & 0 & 51 & 0 & 0 \\
\hline 14 & Nephritis chronica & 0 & 13 & 0 & 38 & 0 & 2 \\
\hline 15 & do & - & 31 & - & 45 & - & 2 \\
\hline 16 & do & - & 12 & - & 19 & - & 3 \\
\hline 17 & Magenkrebs & 0 & 7 & 0 & 16 & 0 & 2 \\
\hline 18 & Nagengeschwiir & 7 & 11 & 0 & 18 & 0 & 0 \\
\hline 19 & do & - & 28 & - & 29 & - & 1 \\
\hline 20 & Morbus Basedowii & 83 & 63 & 0 & 125 & 0 & reich1. \\
\hline 21 & Pleuritis exsudativa & 0 & 21 & 0 & 19 & 0 & 15 \\
\hline 22 & Amyotr. Lateralsclerose & 85 & 82 & 0 & 43 & 0 & 26 \\
\hline 23 & Spast. Spinalparalyse & 4 & 73 & 0 & 84 & 0 & reichl. \\
\hline 24 & $\begin{array}{l}\text { Gesund } \\
\text { Gestat }\end{array}$ & 4 & 11 & 0 & 11 & 0 & 0 \\
\hline 25 & do & 2 & 5 & () & 14 & 0 & 3 \\
\hline 26 & do & 6 & 9 & 0 & 12 & 0 & 1 \\
\hline 27 & do & 10 & 5 & 0 & 13 & 0 & 0 \\
\hline 28 & do & 10 & 10 & 0 & 15 & 0 & 0 \\
\hline
\end{tabular}


Bei Ausführung dieser Methode müssen wir besonders folgende zwei Punkte berücksichtigen : erstens, dass die Zahl der eingesäten Bakterien sehr gering d.h. einige Hunderte, sein muss, weil die thermostabilen bakteriziden Serumstoffe nur in ziemlich beschränkter Menge vorhanden sind; zweitens, dass auf alle Fälle die Prüfung mit der 24 Stunden im Brutschrank belassenen Probe gemacht werden muss, weil es ziemlich langer Zeit bedarf, bis die höchste Wirksamkeit erreicht ist.

\section{Untersuchungen uber thermostabile bakterizide Serumstoffe sowohl der Menschen als der Tiere, im Vergleich mit den Serumalexinen.}

Vor allem untersuchten wir, in welchen Menschen- und 'Tierarten dicse Serumstoffe gefunden werden und anch, wie weit diese mit den Serumalexinen zu vergleichen sind.

\section{Versuch 1.}

Zu diesem Zweck prüften wir mit frischen Sera und solchen, deren Alexine durch $\frac{1}{2}$ stündige Erhitzung bei $56^{\circ} \mathrm{C}$ vernichtet worden waren.

Sämtliche Versuchsergebnisse sind in Tabelle I u. II enthalten. Aus Tabelle I lïsst sich Folgendes zusammenfassen : alle 18 aktiven Sera sowohl der Gesunden als auch der Kranken besitzen bakterizide Fähigkeit gegenüber Typhusbazillen, aber von den untersuchten 28 inaktiven Sera wirken 26 bakterizid, nur zwei (Nr. 20 u. 23) nicht. Tabelle II zeigt die Ergebnisse der Tiersera. Alle aktiven Tiersera haken bakterizide Wirkung auf Typhusbazillen, aber bei inaktiven Sera ist es ganz verschieden. Alle 6 inaktiven Schweinesera wirken bakterizid. Von 5 Hundesera besitzen 4 bakterizide Wirkung, aber 1 wirkt entwicklungshemmend. Von 4 Pferdesera wirken 1 bakterizid, aber die auderen 3 nicht bakterizid. Von 6 Hammelsera wirken 2 entwicklungshemmend, aber die anderen 4 uicht keintötend. Die Sera von anderen Versuchstieren (5 Kaninchen, 4 Meerschweinchen und 4 Rindern) wirken sümtlich nicht bakterizid.

Bei diesen Versuchen von Menschen und Tieren war es besonders auffallend, dass die thermostabilen bakteriziden Serumstoffe nicht immer mit Serumalexinen zusammen vorhanden waren und dass bei allen aktiven Sera die Wirkung sehr schnell cintrat, d.h. die Kolonienzahl schon nach 4 Stunden nicht oder nur vereinzelt gefunden wurde, aber dass bei inaktiven Sera die Kolonienzahl sich nach 4 Stunden nicht verminderte, sondern vielmehr etwas vermehrte und erst nach 24 Stunden die Bakterizidie sich äusserte. 
Tabelle II.

Tierserum : aktiv und $\frac{1}{2}$ Stunde bej $56^{\circ} \mathrm{C}$ inaktiviert, $0,5 \mathrm{~cm}$ benutzt.

Aussaat: Bouillonkultur von Bac. Typhi.

\begin{tabular}{|c|c|c|c|c|c|c|c|}
\hline \multirow{3}{*}{ Tierarten } & \multirow{3}{*}{ Tier-Nr. } & \multicolumn{6}{|c|}{ Kolonienzahl auf den Platten } \\
\hline & & \multicolumn{2}{|c|}{$\begin{array}{c}\text { sofort nach } \\
\text { Aussaat }\end{array}$} & \multicolumn{2}{|c|}{$\begin{array}{c}\text { nach } 4 \\
\text { Stunden }\end{array}$} & \multicolumn{2}{|c|}{$\begin{array}{l}\text { nach } 24 \\
\text { Stunden }\end{array}$} \\
\hline & & aktiv & $\begin{array}{c}\text { in- } \\
\text { aktiv }\end{array}$ & aktir & $\begin{array}{c}\text { in- } \\
\text { aktiv }\end{array}$ & aktiv & $\begin{array}{c}\text { in- } \\
\text { aktiv }\end{array}$ \\
\hline Schwein & $\begin{array}{l}1 \\
2 \\
3 \\
4 \\
5 \\
6\end{array}$ & $\begin{array}{r}3 \\
2 \\
13 \\
25 \\
29 \\
20\end{array}$ & $\begin{array}{r}12 \\
7 \\
13 \\
32 \\
22 \\
54\end{array}$ & $\begin{array}{l}0 \\
0 \\
0 \\
0 \\
0 \\
0\end{array}$ & $\begin{array}{l}25 \\
13 \\
32 \\
44 \\
62 \\
71\end{array}$ & $\begin{array}{l}0 \\
0 \\
0 \\
0 \\
0 \\
0\end{array}$ & $\begin{array}{r}0 \\
8 \\
0 \\
4 \\
10 \\
7\end{array}$ \\
\hline Hund & $\begin{array}{l}1 \\
2 \\
3 \\
4 \\
5\end{array}$ & $\begin{array}{l}34 \\
80 \\
44 \\
16 \\
13\end{array}$ & $\begin{array}{l}47 \\
54 \\
81 \\
15 \\
13\end{array}$ & $\begin{array}{l}7 \\
8 \\
0 \\
5 \\
8\end{array}$ & $\begin{array}{r}73 \\
135 \\
14 \\
16 \\
80\end{array}$ & $\begin{array}{l}0 \\
0 \\
0 \\
0 \\
0\end{array}$ & $\begin{array}{r}42 \\
645 \\
11 \\
0 \\
0\end{array}$ \\
\hline Pferd & $\begin{array}{l}1 \\
2 \\
3 \\
4\end{array}$ & $\begin{array}{c}- \\
5 \\
4\end{array}$ & $\begin{array}{r}24 \\
9 \\
4 \\
7\end{array}$ & $\begin{array}{c}- \\
0 \\
0\end{array}$ & $\begin{array}{l}30 \\
16 \\
18 \\
19\end{array}$ & $\overline{-}$ & $\begin{array}{c}\text { reichl. } \\
\text { reichl. } \\
4 \\
1000\end{array}$ \\
\hline Hammel & $\begin{array}{l}1 \\
2 \\
3 \\
4 \\
5 \\
6\end{array}$ & $\begin{array}{l}28 \\
20 \\
91 \\
37 \\
40 \\
38\end{array}$ & $\begin{array}{r}56 \\
66 \\
96 \\
9 \\
13 \\
30\end{array}$ & $\begin{array}{l}2 \\
0 \\
1 \\
3 \\
0 \\
1\end{array}$ & $\begin{array}{r}126 \\
78 \\
181 \\
45 \\
61 \\
57\end{array}$ & $\begin{array}{l}0 \\
0 \\
0 \\
0 \\
0 \\
0\end{array}$ & $\begin{array}{c}493 \\
\infty \\
\infty \\
\infty \\
42 \\
\infty\end{array}$ \\
\hline Kaninchen & $\begin{array}{l}1 \\
2 \\
3 \\
4 \\
5\end{array}$ & $\begin{array}{r}9 \\
2 \\
8 \\
14 \\
9\end{array}$ & $\begin{array}{r}10 \\
13 \\
24 \\
2 \\
5\end{array}$ & $\begin{array}{l}0 \\
0 \\
0 \\
4 \\
2\end{array}$ & $\begin{array}{l}23 \\
45 \\
90 \\
19 \\
14\end{array}$ & $\begin{array}{l}0 \\
0 \\
0 \\
0 \\
0\end{array}$ & $\begin{array}{l}\infty \\
\infty \\
\infty \\
\infty \\
\infty\end{array}$ \\
\hline Meerschweinchen & $\begin{array}{l}1 \\
2 \\
3 \\
4\end{array}$ & $\begin{array}{r}7 \\
13 \\
- \\
-\end{array}$ & $\begin{array}{r}0 \\
4 \\
20 \\
22\end{array}$ & $\begin{array}{r}8 \\
5 \\
- \\
-\end{array}$ & $\begin{array}{r}13 \\
37 \\
154 \\
152\end{array}$ & $\begin{array}{r}0 \\
0 \\
- \\
-\end{array}$ & $\begin{array}{c}\text { reichl. } \\
\infty \\
\infty \\
\infty\end{array}$ \\
\hline Rind & $\begin{array}{l}1 \\
2 \\
3 \\
4\end{array}$ & $\begin{array}{l}5 \\
8 \\
1 \\
7\end{array}$ & $\begin{array}{r}9 \\
28 \\
8 \\
11\end{array}$ & $\begin{array}{l}0 \\
0 \\
0 \\
0\end{array}$ & $\begin{array}{l}16 \\
38 \\
22 \\
13\end{array}$ & $\begin{array}{l}0 \\
0 \\
0 \\
0\end{array}$ & $\begin{array}{c}\text { reichl. } \\
\text { reichI. } \\
\infty \\
\text { reichl. }\end{array}$ \\
\hline
\end{tabular}




\section{II. Über die Beziehung der Immunität zu thermostabilen bakteriziden Serumstoffen.}

Nach Seiffert, ${ }^{+9-5)}$ der die bakterizide Wirkung gegenüber verschiedenen Bakterienarten mit inaktiven Sera von zahlreichen Menschen- und Tierarten prüfte, findet ein bestimmter Zusammenhang zwischen thermostabilen bakteriziden Serumstoffen und natürlicher und künstlich erzeugter Immunität statt, d.h. wem ein endotoxinbildender Erreger durch ein inaktives Serum von einem Organismus abgetötet wird, so ist dieses Individuum für dicsen Erreger empläinglich, aber wenn dieser Erreger nicht abgetötet wird, so zeigt das, dass dieser Organismus durch dieson Erreger nicht infizierbar ist, aber beim Erreger von septikïmischer Natur ist dieses Verhältuis gerade umgekehrt, und Seiffer tgelang es nicht, beim Erreger der Toxikose ein bestimmtes Verhailtnis festzustellen. Er untersuchte noch eingehender diese Korrelation mit Typhusbarillen und wies nach, dass, wïhrend normale Mensehensera anf Typhusbazillen bakterizid wirken, die Sera von den Menschen, die an Typhus erkrankt oder gegen Typhus schutzgeimptt waren, keine Wirkıng haben. Diese Erscheinung hat daher klinisch grosse Bedeutung, un die Empfänglichkeit eines Individuums für Typhuserkrankung zu erkennen. Aber Schou ${ }^{53}$ und Selte ${ }^{53}$ fanden durch Nachprüfung diese Seiffer tschen Versuche nicht bestätigt.

Wir stellten die folgenden Versuche an, um die interessanten Se iffer $\mathrm{t}$ schen Untersuchungen nachzuprüfen.

\section{Versuch 2.}

In erster Linie prüften wir die bakterizide Kraft der inaktiven Sera von Typhuskranken, von früher an Typhus Erkrankten und von gegen Typhus Schutzgeimpften. Tabelle III lässt erkennen, dass unter den geprüften 28 Sera nur die zwei, welche von Typhuskranken im Rekonvaleszenzstadium entnommen waren, entwicklungshemmend, aber die anderen bakterizid wirken.

\section{Versuch 3.}

Ferner führten wir den folgenden Versuch aus, um festzustellen, ob die thermostabilen Stoffe der Hundesera, welche von vornherein bakterizide Fähigkeit gegen Typhusbazillen haben, durch Immunisierung des Hundes mit Typhusbazillen verloren gehen. 


\section{Tabelle III.}

Menschenserum: $\frac{1}{2}$ Stunde bei $56^{\circ} \mathrm{C}$ inaktiviert, $0,5 \mathrm{ccm}$ benutzt.

Aussaat: Bouillonkultur von Bac. Typhi.

\begin{tabular}{|c|c|c|c|c|c|}
\hline \multirow{2}{*}{$\begin{array}{l}\text { Menschen- } \\
\text { Nr. }\end{array}$} & \multirow{2}{*}{\multicolumn{2}{|c|}{ Art der Sera }} & \multicolumn{3}{|c|}{ Kolonienzahl auf den Platten } \\
\hline & & & $\begin{array}{l}\text { sofort nach } \\
\text { Aussaat }\end{array}$ & $\begin{array}{l}\text { nach } 4 \\
\text { Stunden }\end{array}$ & $\begin{array}{l}\text { nach } 24 \\
\text { Stunden }\end{array}$ \\
\hline $\begin{array}{l}1 \\
2 \\
2 \\
3 \\
4 \\
4 \\
5 \\
5 \\
6 \\
7 \\
8 \\
9 \\
9\end{array}$ & $\begin{array}{l}\text { Typhus abdom., } \\
\text { ", " } \\
\text { " } \\
\text { Typhus-" } \\
\text { Rekonvalescenz, } \\
\text { " } \\
" \\
" \\
" \\
" \\
"\end{array}$ & $\begin{array}{l}\text { 2. Woche } \\
3 . \quad " \\
5 . \quad " \\
4 . \quad " \\
5 . \quad " \\
7 . \quad " \\
6 . \quad " \\
6 . \quad " \\
6 . \quad " \\
7 . \quad " \\
8 . \quad " \\
11 . \quad "\end{array}$ & $\begin{array}{r}38 \\
23 \\
11 \\
9 \\
37 \\
\\
20 \\
7 \\
36 \\
16 \\
43 \\
28 \\
14\end{array}$ & $\begin{array}{l}56 \\
40 \\
21 \\
31 \\
35 \\
\\
22 \\
27 \\
35 \\
39 \\
43 \\
22 \\
7\end{array}$ & $\begin{array}{r}6 \\
11 \\
1 \\
0 \\
8 \\
\\
0 \\
0 \\
2 \\
7 \\
15 \\
3 \\
0\end{array}$ \\
\hline $\begin{array}{l}10 \\
11 \\
12\end{array}$ & $\begin{array}{c}\text { Typhus abdom., } \\
\text { " } \\
, "\end{array}$ & 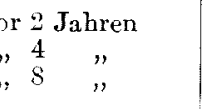 & $\begin{array}{r}9 \\
17 \\
25\end{array}$ & $\begin{array}{l}11 \\
17 \\
62\end{array}$ & $\begin{array}{l}1 \\
0 \\
0\end{array}$ \\
\hline $\begin{array}{l}13 \\
14 \\
15 \\
16 \\
17 \\
18 \\
19 \\
20 \\
21 \\
22 \\
23 \\
24 \\
25\end{array}$ & $\begin{array}{l}\text { Schut zimpfung mi } \\
\text { ", } \\
\text { ", } \\
\text { ", } \\
\text { ", } \\
\text { " } \\
\text { " } \\
\text { ", } \\
\text { ", }\end{array}$ & 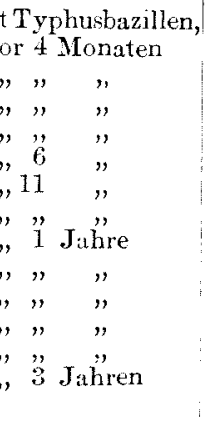 & $\begin{array}{r}4 \\
11 \\
20 \\
19 \\
8 \\
12 \\
5 \\
24 \\
26 \\
33 \\
38 \\
9 \\
17\end{array}$ & $\begin{array}{r}8 \\
4 \\
18 \\
9 \\
167 \\
19 \\
27 \\
44 \\
36 \\
37 \\
88 \\
11 \\
34\end{array}$ & $\begin{array}{r}4 \\
4 \\
0 \\
10 \\
6 \\
78 \\
2 \\
2 \\
48 \\
4 \\
0 \\
1 \\
8\end{array}$ \\
\hline
\end{tabular}

Wir impften einen Hund mit bei $60^{\circ} \frac{1}{2}$ St. lang erhitzten Typhusbazillen, zuerst mit $\frac{1}{2}$ Agar und dann nach einer Woche mit 1 Agar. Einerseits beobachtete man den Grad der Immunisierung an der Agglutinationsreaktion, anderseits prüfte man die bakterizide Wirkung der inaktiven Sera, welche nach mehreren kleinen Pausen dem Hunde entnommen worden waren.

Aber, wie 'Tabelle IV u. Tabelle $\mathrm{V}$ zeigen, blieb jede Wirkung aus, es zeigte sich weder eine Vermehrung noch eine Verminderung. 


\section{Tabelle IV.}

Hund: Nr. I; $\delta$, weiss, $5,5 \mathrm{~kg}$.

Serum: $\frac{1}{2}$ Stunde bei $56^{\circ} \mathrm{C}$ inaktiviert, $0,5 \mathrm{ccm}$ benutzt.

Aussaat: Bouillonkultur von Bac. Typhi.

\begin{tabular}{c|c|c|c|c}
\hline \multirow{2}{*}{ Zeit } & Agglutinationstiter & \multicolumn{3}{|c|}{ Kolonienzahl auf den Platten } \\
\cline { 2 - 5 } & $\begin{array}{c}\text { sofort nach } \\
\text { Ausaat }\end{array}$ & $\begin{array}{c}\text { nach 4 } \\
\text { Stunden }\end{array}$ & $\begin{array}{c}\text { nach 24 } \\
\text { Stunden }\end{array}$ \\
\hline $\begin{array}{c}\text { ror Injektion } \\
\text { ror Injektion }\end{array}$ & $1: 50(-)$ & 12 & 7 & 1 \\
$1: 50(-)$ & 8 & 13 & 12
\end{tabular}

$\frac{1}{2}$ Schrägagar ron Typhusbazillen s.c. injiziert.

nach 1 Woche

$1: 2000$

22

20

0

nach 1 Woche 1 Schrigagar ron Typhusbazillen s.c. injiziert.

nach 2 Wochen nach 4 Wochen

nach 5 Wochen nach 12 Wrichen nach 13 Wochen nach 14 Wochen

$1: 10000$
$1: 5000$
$1: 2000$
$1: 200$
$1: 200$
$1: 100$

15
17
31
20
17
8

\begin{tabular}{r|r}
15 & 0 \\
9 & 0 \\
106 & 38 \\
26 & 18 \\
28 & 17 \\
6 & 5
\end{tabular}

\section{Tabelle V.}

Hund: Nr. II ; 3 , braun, $S$ kg.

Serum: $\frac{1}{2}$ Stunde bei $56^{\circ} \mathrm{C}$ inaktipiert, $0,5 \mathrm{ccm}$ benutzt.

Aussaat: Bouillonkultur von Bac. Typhi.

\begin{tabular}{c|c|c|c|c}
\hline \multirow{2}{*}{ Zeit } & Agglutinationstiter & \multicolumn{3}{|c}{ Kolonienzahl auf den Platten } \\
\cline { 2 - 5 } & $\begin{array}{c}\text { sofort nach } \\
\text { Aussaat }\end{array}$ & $\begin{array}{c}\text { nach 4 } \\
\text { Stunden }\end{array}$ & $\begin{array}{c}\text { nach 24 } \\
\text { Stunden }\end{array}$ \\
\hline $\begin{array}{c}\text { vor Injektion } \\
\text { vor Injektion }\end{array}$ & $1: 50(-)$ & 3 & 7 & 9 \\
$1: 50(-)$ & 9 & 7 & 78
\end{tabular}

$\frac{1}{2}$ Schrïgagar ron Typhusbazillen s.c. injiziert.

nach 4 Tagen

" 1 Woche
$1: 200$
$1: 1000$
8

nach 1 Woche 1 Schrägagar ron Typhusbazillen s.c. injiziert.

nach 11 Tagen

, 2 Wochen

" 18 Tagen

" 3 Wochen

," 4 Wochen

" 32 Tagen

" 5 Wochen

" 39 Tagen

" 6 Wochen

" 46 Tagen

"7 Wochen

" 53 Tagen

") 8 Wochen

") Wochen

"10 Wochen

, 12 Wochen
$1: 1000$

$1: 2000$

$1: 1000$

$1: 1000$

$1: 1000( \pm)$

1.500

I:500

$1: 500$

$1: 500$

1:200

]:200

$1: 200$

1:200

$1: 200$

1:200

$1: 200$
24

22

0

44

6

0

6

0

35

4

9

3

4

3

0 
Nach den Seiffertschen Untersuchungen besitzen inaktive Scra von gegen Typhus unempfänglichen Tieren keine bakterizide Wirkung auf Typhusbazillen, aber unsere Untersuchung (Versuch 1, Tabelle II) zeigt, dass die inaktiven Sera von Schweinen und Hunden, welche beide gegen Typhus unempfänglich sind, keimtötend wirken.

Gestützt auf obige Versuche können wir den Schlus ziehen, dass thermostabile bakterizide Srumstoffe, im Gegensatz zu Seiffert, in keiner Beziehung zur natürlichen oder künstlich erzeugten Immunität stehen.

\section{Sind thermostabile bakterizide Serumstoffe mit den bakteriziden Leukozytenstoffen identisch?}

Die vielen Verschiedenheiten der Eigenschaften zwischen bakteriziden Lenkozytenstoflen und Serumalexinen wurden von zahlreichen Forschern aufgezählt, und es wurde bestätigt, dass die beiden Stoffe nicht zu identifizieren sind, aber über die Eigensehaften der thermostabilen bakteriziden Serumstoffe und ihre Beziehung zu den bakteriziden Leukozytenstoffen wurden nur wenige Berichte veröffentlicht. Dold $d^{+\infty}$ wies nach, dass die bakterizide Wirkung von Blut, Plasma und Serum der Menschen gegen virulente Pneumokokkenstämme beim akuten fieberhaften Zustande sich vermehrt. Ferner entdeckte er, dass, weil diese Stoffe durch halbstündiges Erhitzen bei $56^{\circ} \mathrm{C}$ nicht zerstört werden, diese Stoffe mit Leukin im Sinne Sch neiders identisch sind.

Selter $\mathrm{r}^{5+1}$ stellte vergleichende Versuche an über die bakterizide Wirkung zwischen den thermostabilen menschlichen Srumstoffen und den aus frischem Abszesseiter extrahierten Laukozytenstoffen, die von dem betreffenden Menschen entnommen wurden, und fand zwischen diesen beiden Stoffen folgende drei gemeinsame Eigenschaften-erstens: Dass beide Stoffe gleich thermostabil sind, aber die Serumstoffe erst nach halbstündigem Erhitzen bei $70^{\circ} \mathrm{C}$ ihre Wirkung verlieren und die Wirkung der Leukozytenstoffe gar erst durch halbstündiges Erhitzen bei $80^{\circ} \mathrm{C}$ zerstört wird; zweitens: Dass beide Stoffe auf cingesiate Bakterien in der Regel gleichartig wirken, d.h. anf Dysenterie- u. Pseudodysenteriebazillen stärker als auf Typhusbazillen, Paratyphus-A-bazillen, Paratyphus-B-bazillen u. Colibazillen; drittens: Dass beide Stoffe durch das Absorptionsverfihren mit Bakterien nicht absorbiert werden können. Dadurch glaubte Selter, dass diese beiden Stoffe identisch sind und nicht zur Rozeptorengruppe nach Ehrlich, sondern zum einfach gebauten, fermentartigen Antikörper gehören. Neuerdings wurde vou Pettersson behauptet, dass im Serum 
zwei verschiedene bakterizide Stoffe vorhanden sind: der eine sei das Buchnersche Alexin ( $\alpha$-Lysin), der andere $\beta$-Lysin. Wir können annchmen, dass dieses sogenannte $\beta$-Lysin seiner Eigenschaft nach mit dem Leukozytenstoff identisch ist.

Folgende Versuche wurden angestellt, um zu prüfen, ob dic thermostabilen bakteriziden Serumstoffe und die bakteriziden Lenkozytenstoffe gemeinsame Eigenschaften haben und ob beide Stoffe identisch sind.

Gewinnungs- und Prüfungsmethoden der Leukozytenstoffe. Die balkterizide Kraft und die Eigenschaften der Leukozytenstoffe setzen verschiedene Bedingungen voraus; besonders sind sie abhängig von den Tierarten, von denen Leukozyten gewonnen werden, und den Extraktionsmethoden der Leukozyten und den Arten der Testbakterien. Für unsere Untersuchungen wählten wir als Versuchstiere zur Gewinnung von Leukuzyten Kaninchen aus, weil $\mathrm{\epsilon}$, wie allgemein bekannt, bei Kaninchen verhältnismässig leicht ist, von für die Bakterizidie störend wirkenden Erythrozyten freie polymorphkernige Leukozyten zu gewimnen, und weil auch von Kaninchenlenkozyten extrahierte bakterizide Stoffe im allgemeinen stärker als solche von anderen Tieren wirken.

Unter den vielen Methoden zur Extrahierung bakterizider Stoffe aus Leukozyten sind die Buchnersche und Schneidersehe als die zwei besten bekannt. Aber für unsere Versuche ist die Schneidersche Methode nicht geeignet, weil bei ihr die Leukozytenstoffe durch Digestion in Leukozyten aufschwemmender Kochsalzlösung unter Zusatz von inaktivem $5 \%$ Serum gewonnen werden. Daher kann Zusatz von Serum, auch wenn es wenig und inaktiv ist, irgend einen Einfluss auf die eigentliche Wirkung der Leukozytenstoffe ausüben. Dengemäss wählten wir die Buchnersche Methode aus.

Um leuknzytenreiches Exsulat zu bekommen, injiziert man am Morgen $50 \mathrm{ccm}$ Bouillon in die Bauchhöhle von Kaninchen und am Abend wieder eine gleiche Menge ; dann kann man am nächsten Morgen gewöhnlich das Exsudat entnehmen. Hierauf lïsst man das Kaninchen innerhalb 24 Stunden aus Arteria carotis verbluten. Damn wird durch aseptische Operation die Bauchhöhle geöffuet und mit physiologiseher Kochsalzlösung ausgespült. Das mit der Sjülflüssigkeit verdünnte Exsudat wird abpipettiert und dam sofort zentrifugiert. Die durch die Zentrifugierung angesammelten Lcukozyten werden wiederum in physiologischer Kochsalzlösung aufgeschwemmt und wieder zentrifugiert. Dieses Verfuhren wird norh zweimal wiederholt. Auf diese Weise werden Leukozyten von Bouillonresten und anderen Substanzen befreit. 
Die Exsudatzellen, die durch diese Methode gewonmen werden, bestehen fast ausschliesslich aus pseudoeosinophilen Leukozyten, aber ausserdem findet man noch, aber nur ganz spärlich, grosse mononukleäre Leukozyten, Lymphozyten und Erythrozyten.

Die so gewomnenen Leukozyten werden dann nach der Buchnersehen Methode extrahiert. Die Leukozyten werden in einigen cem physiologischer Kochsalzlösung aufgeschwemmt, und diese Aufschwemmung wird 20 Minuten im Eiskochsalzgemisch gefroren und danach 10 Minuten lang in $37^{\circ} \mathrm{C}$ warmem Wasser aufgetaut. Diescs Verfahren wird dreimal wiederholt, dann wird 20 Minuten lang bei $37^{\circ} \mathrm{C}$ digeriert und durch starke Zentrifugierung völlig klarer Extrakt gewonnen.

Bei diesem Verfahren muss man besonders darauf achten, die Digestion über eine halbe Stunde lang durchaus zu vermeiden, weil durch zu lange dauernde Digestion Bakteriennährstcffe aus spontan absterbenden Leukozyten in die Flüssigkeit übertreten.

Wenn man dieses Extrakt bei $56^{\circ} \mathrm{C}$ oder bei noch höherer Temperatur erhitzt, wird es getrübt. Diese Trübung ist durch nochmalige Zentrifugierung zu beseitigen.

Was die Prüfungsmethode der bakteriziden Wirkung von Leukozytenstoffen anbetrifft, so ist die gleiche Methode wie bei den thermostabilen bakteriziden Serumstoffen angewandt worden.

A. Resistenz gegen Erwärmung beider Stoffe.

Eine ausgezeichnete Ejgenschaft der bakteriziden Leukozytenstoffe liegt in ihrer Thermostabilität, aber ihr Grad ist je nach den Tierarten, aus denen Leukozyten gewomien werden, und je nach der Gewinnungsmethode der Leukozytenstoffe sehr variatel. Über die Hitzebeständigkeit der Kaninchenleukozytenstoffe selbst wurden verschiedene Berichte veröffentlicht. Nach Untersuchungen von Schattenfroh, ${ }^{8)}$ der die bakterizide Wirkung auf Typhusbazillen mit den durch seine eigene Extraktionsmethode gewonnenen Kanindhenleukozytenextrakten prüfte, geht die Wirkung durch halbstündiges Erwärmen bei $56^{\circ} \mathrm{C}$ verloren. Schneidert:41 wies nach, dass durch die Buchnersche Methode gewonnene Kaninchenleukozytcnextrakte dur h $\frac{1}{2}-1$ stündiges Erhitzen bei $55^{\circ}-60^{\circ} \mathrm{C}$ ihre Wirksamkeit anf Typhusbazillen zuweilen vollständig oder teilweise verlieren, aker durch seine eigene Methode gewonnenes Extrakt erst bei $80^{\circ} \mathrm{C}$. Nach Zinsse $\mathrm{r}^{21)}$ geht ihre Wirkung gegenüber Typhusbazillen bei $75^{\circ} \mathrm{C}$ verloren, und nach $\mathrm{Manwaring} \mathrm{g}^{24)}$ ist ihre Kraft bei $80^{\circ} \mathrm{C}$ noch 
nicht vollständig zerstört. Inbetreff der Thermoresistenz der bakteriziden Serumstoffe gibt es nur eine Angabe von Selter, ${ }^{54)}$ nach welcher die bakterizide Wirkung der Menschensera durch Erhitzen bei $65^{\circ}-70^{\circ} \mathrm{C}$ vollständig zerstört wird.

\section{Tabelle VI.}

$\mathrm{K}$ aninchen : 5 , weiss, $1,8 \mathrm{~kg}$.

Leukozytenextrakt: $0,21 \mathrm{~g}$ Leukozyten in $3 \mathrm{ccm}$ physiol. Kochsalzlösung extrahiert.

Aussaat: Bouillonkultur von Bac. Typhi.

\begin{tabular}{|c|c|c|c|c|c|}
\hline \multirow{2}{*}{\multicolumn{3}{|c|}{$\begin{array}{l}\text { Art und Menge der } \\
\text { zu prufenden Flüssiglieiten }\end{array}$}} & \multicolumn{3}{|c|}{ Kolonienzahl auf den Platten } \\
\hline & & & $\begin{array}{l}\text { sofort nach } \\
\text { Aussaat }\end{array}$ & $\begin{array}{l}\text { nach } 10 \\
\text { Stunden }\end{array}$ & $\begin{array}{l}\text { nach } 24 \\
\text { Stunden }\end{array}$ \\
\hline \multirow{2}{*}{\multicolumn{3}{|c|}{$\begin{array}{l}0,5 \mathrm{ccm} \text { akt. Leuk.-Extrakt } \\
" \quad, \text { Leuk.-Extrakt bei } 56^{\circ} \mathrm{C} \text { erhitzt }\end{array}$}} & 2 & \multirow{3}{*}{$\begin{array}{c}0 \\
\text { reichl. } \\
\infty\end{array}$} & 0 \\
\hline & & & 12 & & $\infty$ \\
\hline$"$ & $"$ & $" 65^{\circ} \mathrm{C}$ & 7 & & $\infty$ \\
\hline$"$ & $"$ &, $70^{\circ} \mathrm{C}$, & 13 & $\infty$ & $\infty$ \\
\hline$"$ & & $" 80^{\circ} \mathrm{C}$, & 7 & $\infty$ & $\infty$ \\
\hline$n$ & $"$ akt. Kar & $m$ & 10 & 0 & 0 \\
\hline$"$ & " Kan.-Se & $56^{\circ} \mathrm{C}$ erbitzt & 9 & 479 & $\infty$ \\
\hline$"$ & $" 0,85 \%$ & alzlösung & 8 & $\infty$ & $\infty$ \\
\hline
\end{tabular}

\section{Tabelle VII.}

Kaninchen: 1 , bunt, $1,9 \mathrm{~kg}$.

Leukozytenextrakt: $0,36 \mathrm{~g}$ Leukozyten in $4 \mathrm{ccm}$ physiol. Kochsalzlösung extrahiert.

Aussaat: Bouillonkultur ron Bac. Typhi.

\begin{tabular}{|c|c|c|c|c|c|}
\hline & \multirow{2}{*}{\multicolumn{2}{|c|}{$\begin{array}{l}\text { Art und Menge der } \\
\text { zu prüfenden Flüsigkeiten }\end{array}$}} & \multicolumn{3}{|c|}{ Kolonienzahl auf den Platten } \\
\hline & & & $\begin{array}{l}\text { sofort nach } \\
\text { Aussaat }\end{array}$ & $\begin{array}{l}\text { nach } 14 \\
\text { Stunden }\end{array}$ & $\begin{array}{l}\text { nach } 24 \\
\text { Stunden }\end{array}$ \\
\hline \multirow{2}{*}{\multicolumn{3}{|c|}{$\begin{array}{l}0,5 \mathrm{ccm} \text { akt. Leuk.-Extrakt } \\
, ", \text { Leuk.-Extrakt bei } 56^{\circ} \mathrm{C} \text { erhitzt }\end{array}$}} & 1 & 0 & 0 \\
\hline & & & 5 & 18 & 0 \\
\hline$"$ & $"$ & $" 65^{\circ} \mathrm{C}$, & 4 & 16 & 12 \\
\hline$"$ & $"$ & $" 70^{\circ} \mathrm{C}$ & 11 & $\infty$ & $\infty$ \\
\hline " & $n$ & $" 80^{\circ} \mathrm{C} "$ & 3 & $\infty$ & $\infty$ \\
\hline , & " akt. Kar & $m$ & 15 & 0 & 0 \\
\hline$"$ & "Kan.-Se & ei $56^{\circ} \mathrm{C}$ erhitzt & 8 & reichl. & $\infty$ \\
\hline$"$ & $\Rightarrow \quad 0,85 \% 6]$ & alzlösung & 7 & reich]. & $\infty$ \\
\hline
\end{tabular}

\section{Versuch 4.}

Durch Injektion von Bouillon in die Bauchhöhle eines Kaninchens gewonnene Leukozyten wurden nach Buchnerscher Methode extrahiert. 
Dieses Leukozy tenextrakt wurde in Mengen von $0,5 \mathrm{ccm}$ in kleine Glasröhrchen gefüllt und bei verschiedenen Temperaturen im Wasserbad 30 Minuten lang erwärmt und dann nach Besaitigung der durch Erwärmung hervorgebrachten Trübung mittels Zentrifugierung seine bakterizide Wirkung auf Typhusbazillen geprüft. Gleichzeitio wurde noch das beim Verbluten des Kaninchens aus Arteria carotis gewonnene Blutserum in gleicher Weise geprüft.

Unsere Versuchsergebnisse (Tabelle VI u. VII) zeigen, dass während Kaninchensera durch halbstündiges Erhitzen bei $56^{\circ} \mathrm{C}$ ilıre Wirksamkeit immer verloren, die Wirkung der Lenkozytenstoffe bald durch Erhitzen bei $56^{\circ} \mathrm{C}$, bald bei $70^{\circ} \mathrm{C}$ verloren ging.

\section{Tabelle VIII.}

Menschensera: Nr. I ; H. N., ¿̇, Typhusrekonraleszenz.

Nr. II ; G. K., s, Tabes doralis.

Nr. III ; T. S., B, Hirntumor.

Aussaat: Bouillonkultur ron Bac. Typhi.

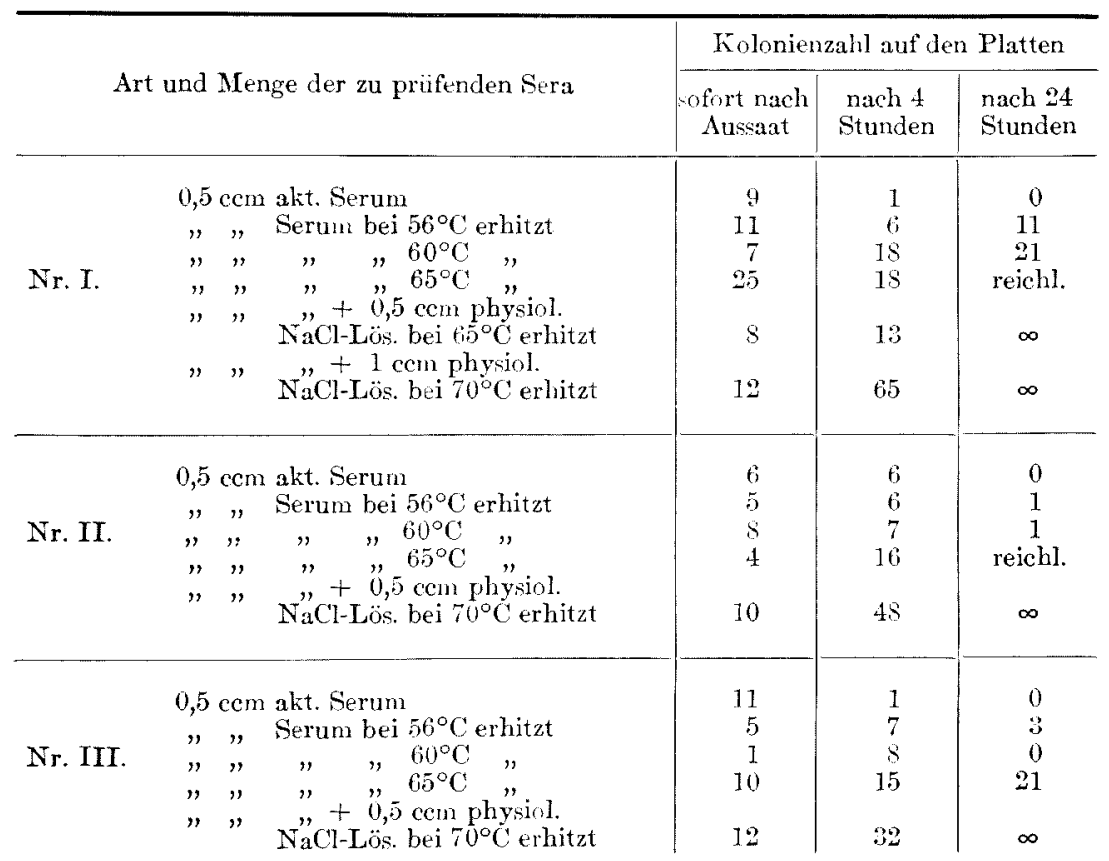




\section{Versuch 5.}

Menschensera werden dickflüssig cder koagulieren durch halbstündiges Erhitzen bei $65^{\circ}-76^{\circ} \mathrm{C}$. Deshalb setzten wir gleich vor dem Erhitzen der Sera bei $65^{\circ} \mathrm{C}$ oder noch höherer 'Temperatur $0,5 \mathrm{ccm}$ oder 1 cem physiologische Kochsalzlösung zu. Da die zu prüfenden Sera mit physiol. NaCl-Lösung zweifach oder dreifach verdünnt waren, entnahmen wir bei der Ausführung des Plattengiessens 2 Ösen aus den zweifach verdünnten Sera und 3 Ösen aus den dreifach verdünnten Sẹra, wonach die Bakterienzahl der unverdünnten Sera gleich sein muss.

Tabelle VIII zeigt, dass die Wirkung der 3 Krankensera durch Erlitzen bei $65^{\circ}-70^{\circ} \mathrm{C}$ vollständig zerstört war. Dieses Resultat stimmt also mit dem Selterschen Ergebnis ${ }^{5 \neq}$ überein.

\section{Tabelle IX.}

Serum : Nr. I; Hund, of, bunt, $5 \mathrm{~kg}$.

Nr. II ; Hund, , bunt, $6,5 \mathrm{~kg}$.

Nr. III ; Hund, $\delta$, weiss, $6,2 \mathrm{~kg}$.

Aussaat: Bouillonkultur von Bac. Typhi.

\begin{tabular}{|c|c|c|c|c|}
\hline \multirow{2}{*}{\multicolumn{2}{|c|}{ Art und Menge der zu prufenden Sera }} & \multicolumn{3}{|c|}{ Kolonienzahl auf den Platten } \\
\hline & & $\begin{array}{l}\text { sofort nach } \\
\text { Aussaat }\end{array}$ & $\begin{array}{c}\text { nach } 4 \\
\text { Stunden }\end{array}$ & $\begin{array}{l}\text { nach } 24 \\
\text { Stunden }\end{array}$ \\
\hline Nr. I. & 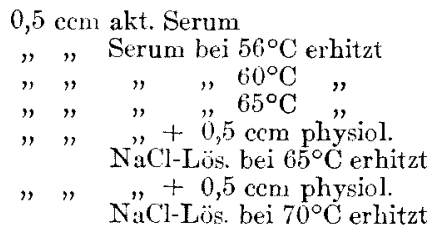 & $\begin{array}{l}9 \\
6 \\
8 \\
3 \\
3 \\
3 \\
7\end{array}$ & $\begin{array}{r}0 \\
2 \\
13 \\
6 \\
48 \\
70\end{array}$ & $\begin{array}{r}0 \\
2 \\
875 \\
\infty \\
\infty \\
\infty\end{array}$ \\
\hline Nr. II. & 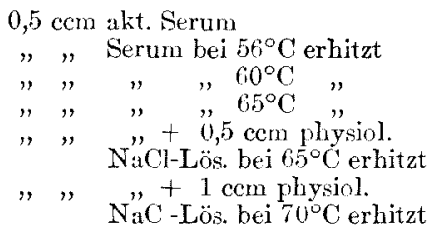 & $\begin{array}{r}7 \\
4 \\
5 \\
11 \\
10 \\
13\end{array}$ & $\begin{array}{l}2 \\
18 \\
11 \\
17 \\
14 \\
87\end{array}$ & $\begin{array}{r}0 \\
251 \\
51 \\
\infty \\
\infty \\
\infty\end{array}$ \\
\hline Nr. III. & 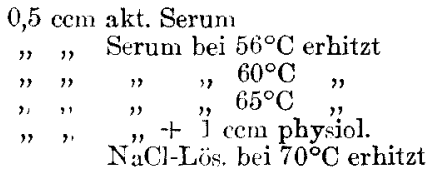 & $\begin{array}{l}16 \\
13 \\
21 \\
16 \\
16\end{array}$ & $\begin{array}{r}3 \\
32 \\
48 \\
93 \\
120\end{array}$ & $\begin{array}{r}0 \\
0 \\
205 \\
\infty \\
\infty\end{array}$ \\
\hline
\end{tabular}




\section{Versuch 6.}

Mit der gleichen Methode, wie bei dem vorigen Versuche, wurde die Hitzebestïndigkeit des Hundserums gepräft.

Tabelle IX zeigt, dass die Wirkung der 3 Hundesera durch halbstündiges Erhitzen bei $60^{\circ} \mathrm{C}$ teilweise und durch das bei $65^{\circ} \mathrm{C}$ vollständig zerstört wurde.

B. Haltbarkeit der Bakterizidie im Eisschrank.

Schneider $\mathbf{r}^{41)}$ bestätigte, dass Kaninchenleukozytenextrakte, die 9 Monate lang in Eisschrank aufbewahrt waren, noch bakterizide Kraft gegen Typhusbazillen hatten.

\section{Versuch \%.}

Bei diesem Versuche wurden Kaninchenleukozytenstoffe auch durch die Buchnersche Methode gewonnen. Leukozytenextrakte wurden in Mengen von $0,5 \mathrm{ccm}$ in schmale Glasröhrchen gefüllt und vor dem Einstellen in den Eisschrank $\frac{1}{2}$ Stunde bei $56^{\circ} \mathrm{C}$ erhitzt, dann wurden alle diese Röhrchen, mit Wachs wohl verschlossen, im Eisschrank aufgehoben.

\section{Tabelle $\mathrm{X}$.}

Kaninchen: $\hat{\theta}$, weise, $1,86 \mathrm{~kg}$.

Leukozyten€xtrakt: $0,35 \mathrm{~g}$ Leukozyten in $4, \overline{3} \mathrm{cem}$ physiol. Kochsalzlösung extrahiert.

Aussaat: Bouillonkultur ron Bac. Typhi.

\begin{tabular}{|c|c|c|c|}
\hline \multirow{2}{*}{$\begin{array}{c}\text { Art und Menge der zu prüfenden } \\
\text { Kan--Leuk,-Extrakte }\end{array}$} & \multicolumn{3}{|c|}{ Kolonienzahl auf den PIatten } \\
\hline & $\begin{array}{l}\text { ofort nach } \\
\text { Aussaat }\end{array}$ & $\begin{array}{l}\text { nach } 15 \\
\text { Stunden }\end{array}$ & $\begin{array}{l}\text { nach } 24 \\
\text { Stunden }\end{array}$ \\
\hline 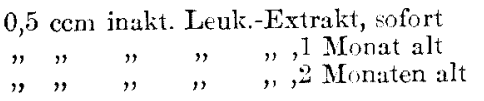 & $\begin{array}{r}2 \\
20 \\
3\end{array}$ & $\begin{array}{r}0 \\
2 \\
112\end{array}$ & $\begin{array}{c}0 \\
0 \\
\text { reichl. }\end{array}$ \\
\hline
\end{tabular}

Tabelle $X$ zeigt, dass die Wirksamkeit der Kaninchenleukozytenextrakte nach 1 Monat unverändert blieb, aber nach 2 Monaten vollständig erloschen war. 


\section{Versuch 8.}

3 Krankensera wurden $\frac{1}{2}$ Stunde bei $56^{\circ} \mathrm{C}$ erhitat und damn in wohlgeschlossenen Röhrchen im Eisschrank aufbewahrt.

\section{Tabelle XI.}

Menchensera: Nr. I; H.S., $\delta$, Amyotrophische Lateralsklerose.

Nr. II; G.S., $\delta$, Magenkrebs.

Nr. III; S.O., b, Paroxysmale Hämoglobinurie.

Ausaat: Bouillonkultur ron Bac. Typhi.

\begin{tabular}{|c|c|c|c|c|c|c|c|c|}
\hline & \multirow{2}{*}{\multicolumn{5}{|c|}{ Art und Menge der zu priifenden Sera }} & \multicolumn{3}{|c|}{ Kolonienzahl auf den Platten } \\
\hline & & & & & & $\begin{array}{c}\text { so fort nach } \\
\text { Aussaat }\end{array}$ & $\begin{array}{c}\text { nach } 4 \\
\text { Stunden }\end{array}$ & $\begin{array}{l}\text { nach } 24 \\
\text { Stunden }\end{array}$ \\
\hline Nr. I. & & $\begin{array}{l}\text { cer } \\
", \\
",\end{array}$ & $\begin{array}{l}\text { nal } \\
", \\
",\end{array}$ & "ch & $\begin{array}{l}\text { um, sofort } \\
\text {, Wochen alt } \\
\text {, } 1 \text { Monat " } \\
\text { 2 Monaten ", }\end{array}$ & $\begin{array}{r}5 \\
6 \\
4 \\
26\end{array}$ & $\begin{array}{l}23 \\
23 \\
13 \\
20\end{array}$ & $\begin{array}{r}0 \\
6 \\
5 \\
20\end{array}$ \\
\hline Nr. II. & $\begin{array}{l}", \\
", \\
",\end{array}$ & $\begin{array}{l}\text { ", } \\
\text { ", } \\
\text { ", }\end{array}$ & $\begin{array}{l}\text { ", } \\
", \\
",\end{array}$ & $\begin{array}{l}" \\
", \\
",\end{array}$ & $\begin{array}{l}\text {, sofort } \\
2 \text { Wochen alt } \\
\text {, } 1 \text { Monat " } \\
\text { 2 Monaten ", } \\
3 \text { " " }\end{array}$ & $\begin{array}{r}15 \\
9 \\
8 \\
21 \\
8\end{array}$ & $\begin{array}{r}24 \\
24 \\
9 \\
23 \\
14\end{array}$ & $\begin{array}{r}2 \\
0 \\
2 \\
130 \\
67\end{array}$ \\
\hline Nr. III. & $\begin{array}{l}" \\
" \\
" \\
"\end{array}$ & $\begin{array}{l}\text { ", } \\
\text { ", } \\
\text { ", }\end{array}$ & $\begin{array}{l}", \\
" \\
"\end{array}$ & $\begin{array}{l}" \\
", \\
",\end{array}$ & $\begin{array}{l}\text {, sofort } \\
, 2 \text { Wochen alt } \\
, 1 \text { Monat " } \\
, 2 \text { Monaten " } \\
3 \text { " " }\end{array}$ & $\begin{array}{r}6 \\
5 \\
8 \\
21 \\
10\end{array}$ & $\begin{array}{r}8 \\
17 \\
14 \\
8 \\
10\end{array}$ & $\begin{array}{r}0 \\
0 \\
0 \\
24 \\
11\end{array}$ \\
\hline
\end{tabular}

Tabelle XI zeigt uns, dass die Menschensera nach 2 oder 3 Monaten ihre bakterizide Wirkung noch fast unveründert bewahrt hatten.

\section{Extraktion mittels Äthers.}

Von Manwaring, ${ }^{2+)}$ Schneider ${ }^{41)}$ und Kling ${ }^{(4)}$ ist bestätigt, dass die bakteriziden Leukozytenstoffe durch Extraktion mittels Äthers nicht in Äther übergehen, sondern sich ungeschwächt im Rückstand finden. Pettersson ${ }^{33)}$ untersuchte die Löslichkeit dieser Stoffe in Allkohol und in einer Mischung von gleichen Teilen Alkohol und Äther und kam zu gleichen Resultaten wie die obigen drei Forscher.

Daraus zogen diese vier Autoren den Schluss, dass die Leukozy tenstoffe nicht als Lipoide zu betrachten seien. 


\section{Versuch 9.}

Das durch die Buch ne rsche Methode gewonnene Leukozy tenextrakt wurde $\frac{1}{2}$ Stunde bei $56^{\circ} \mathrm{C}$ erhitzt und dann zu klarer Flüssigkeit zentrifugiert. Dieses Leukozytenextrakt wurde in einer Menge von $4 \mathrm{ccm}$ mit dreifachem Volumen reinsten Äthers gemischt, gut geschüttelt und das obenbefindliche klare $\ddot{A}$ therextrakt in eine kleine sterile Petrische Schale gegeben. Diese Extraktion wurde noch zweimal wiederholt. Der durch Ather extrahierte Leukozytenrest wurde auch in eine Schale gegeben. Zur Kontrolle wurde noch ein gleich grosses Volumen Äther, wie es bei der Extraktion angewandt worden, d. h. $36 \mathrm{ccm}$, in eine Schale gegeben.

Diese 3 Schalen wurden auf einmal behufs vollständiger Eintrocknung in einen Trockenschrank bei $40^{\circ} \mathrm{C}$ gestellt, dann wurden die eingetrockneten ätherfreien Massen in je $1 \mathrm{ccm}$ physiol. Kochsalzlösung gelöst. Diese Kochsalzlösungen wurden zur bakteriziden Prüfung gegen Bac. Typhi angewandt.

Bei diesem Versuche muss besonders auf die Reinheit des Äthers geachtet werden, weil der Rückstand des unreinen $\ddot{A}$ thers von selber öfters bakterizid wirkt.

\section{Tabelle XII.}

Leukozytenextrakt: Aus 2 Kaninchen gesammelte $0,65 \mathrm{~g}$ Leukozyten in $5 \mathrm{ccm}$ physiol. Kochsalzlösung extrabiert.

Aussaat: Bouillonkultur von Bac. Typhi.

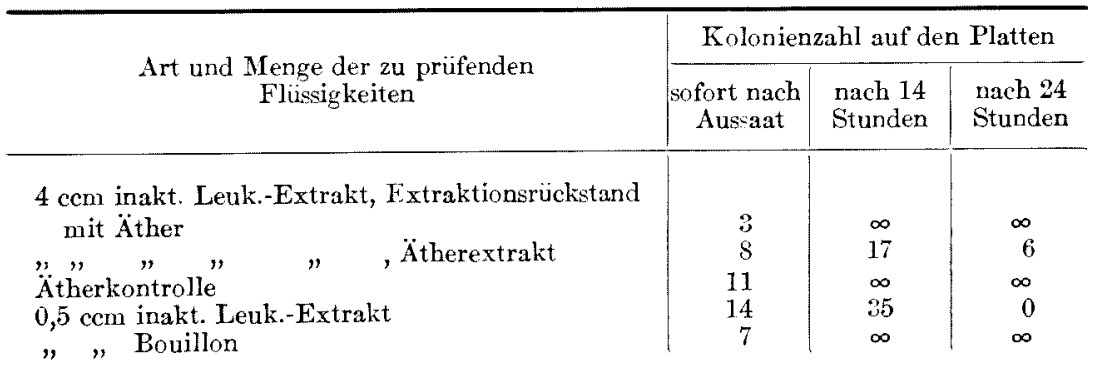

'Tabelle XII zeigt, dass die bakteriziden Leukozytenstoffe sich nicht durch Äther extrahieren lassen, sondern dass sie im Rückstand unveräıdert bleiben. 


\section{Versuch 10.}

$2 \mathrm{ccm}$ inaktives Menschenserum wurde nach gleicher Methode wie bcim vorigen Versuche extrahiert, aber die im Trockenschrank getrockneten Mengen wurden in diesem Versuche nicht in $1 \mathrm{~cm}$ physiol. Kochsalzlösung, sondern in $1 \mathrm{ccm}$ Bouillon gelöst.

\section{Tabelle XIII.}

Menschensera: Nr. I; K.O., 9,39 Lj., Magenkrebs.

Nr. I I; K.N., \&, 46 Lj., Tabes dorsalis.

Nr. III; T.T., \&, $30 \mathrm{Lj}$, Beri-Beri.

Aussaat: Bouillonkultur ron Bac. Typhi.

\begin{tabular}{|c|c|c|c|}
\hline \multirow{2}{*}{$\begin{array}{l}\text { Art und Menge der zu prüfenden } \\
\text { Flüssigkeiten }\end{array}$} & \multicolumn{3}{|c|}{ Eolonienzahl auf den Platten } \\
\hline & $\begin{array}{c}\text { sofort nach } \\
\text { Aussaat }\end{array}$ & $\begin{array}{l}\text { nach } 14 \\
\text { Stunden }\end{array}$ & $\begin{array}{l}\text { nach } 24 \\
\text { Stunden }\end{array}$ \\
\hline $\begin{array}{l}2 \mathrm{ccm} \text { inakt. Nr. I. Serum, Extraktionsrückstand } \\
\text { mit Ather } \\
\text { " " " , Atherextrakt } \\
\text { Atherkontrolle" } \\
0,5 \text { ccm inakt. Nr. I. Serum } \\
" \text { " Bouillon }\end{array}$ & $\begin{array}{r}9 \\
10 \\
13 \\
20 \\
33\end{array}$ & $\begin{array}{l}17 \\
\infty \\
\infty \\
8 \\
\infty\end{array}$ & $\begin{array}{c}40 \\
\infty \\
\infty \\
0 \\
\infty\end{array}$ \\
\hline $\begin{array}{l}2 \mathrm{ccm} \text { inakt. Nr. II. Serum, Extraktionsrïkstund } \\
\text { mit Ather } \\
\text { "̈ " , Atherextrakt } \\
0,5 \text { ccm inakt. Nr. II. Serum } \\
", " \text { Bouillon }\end{array}$ & $\begin{array}{r}16 \\
7 \\
12 \\
17 \\
17\end{array}$ & $\begin{array}{l}10 \\
\infty \\
\infty \\
10 \\
\infty\end{array}$ & $\begin{array}{r}300 \\
\infty \\
\infty \\
0 \\
\infty\end{array}$ \\
\hline $\begin{array}{l}2 \text { ccm inakt. Nr. III. Serum, Extraktionsrïckstand } \\
\text { mit Äther } \\
\text { "̈therkontrolle" } ", \text { Atherextrakt } \\
0,5 \text { ccm inakt. Nr. IIT. Serum } \\
" \text { "Bouillon }\end{array}$ & $\begin{array}{l}19 \\
13 \\
12 \\
15 \\
10\end{array}$ & $\begin{array}{c}16 \\
\infty \\
\infty \\
3 \\
\infty\end{array}$ & $\begin{array}{c}6 \\
\infty \\
\infty \\
0 \\
\infty\end{array}$ \\
\hline
\end{tabular}

Tabelle XIII zeigt, dass die thermostabilen bakteriziden Serumstoffe wie die Lenkozytenstoffe mittels Ithers nicht extrahierbar sind, sondern im Rürkstand bleiben, während ihre Wirksamkeit nur etwas abgeschwächt wurde.

Aus obigen Versuchen geht hervor, dass die Leukozytenstoffe und die thermostabilen Serumstoffe, da sie durch Äther nicht extrahierbar sind, nicht zu den Lipoiden gehören. In dieser Beziehung besitzen diese beiden Stoffe dieselbe Eigenschaft wie die Fermente. 


\section{Filtrierbarkeit.}

Schneider ${ }^{41)}$ wies nach, dass die bakteriziden Kaninchenleukozytenstoffe den Berkefeld schen Filter ungesch wächt passieren, aber nach Manwaringschen Untersuchungen ${ }^{24}$ gehen diese Stoffe nicht durch diesen Filter hindurch. Pettersson ${ }^{3)}$ prüfte die Filtrierbarkeit mit Chamberland- und Berkefeld- Filtern und fand, dass die Ieukozytenstoffe diese beiden Filter bald vollkommen, bald garuicht passieren, dagegen den Pukallschen Filter stets nicht passieren. Diese Petterssonschen Versuche wurden auch von Kling ${ }^{4 j}$ bestïtigt. Durch obige Versuche können wir nicht mit Sicherheit sagen, ob die bakteriziden Leukozytenstoffe filtrierbar sind oder nicht. Nach den Selterschen Versuchen ${ }^{\text {jit }}$ passieren die thermostabilen bakteriziden Menschenserumstoffe den Berkefeldschen Filter.

\section{Versuch 11.}

Die durch die Buchnersche Methode gewonnenen Kaninchenleukozytenextrakte wurden nach halbstïndigem Erhitzen bei $56^{\circ} \mathrm{C}$ zur klaren Flüssigkeit zentrifugiert und dann durch eine neue, sterilisierte Chamberlandsche Kerze filtriert.

\section{Tabelle XIV.}

Leukozytenextrakte: $\mathrm{Nr}$. I ; Kaninchen, $\hat{3}$, braun, $1,8 \mathrm{~kg}$. $0,6 \mathrm{~g}$ Leukozyten in $5 \mathrm{ccm}$ physiol. Kochsalzlösung extrabiert.

$\mathrm{Nr}$. II; Aus 3 Kaninchen gesammelte $2,3 \mathrm{~g}$ Leukozyten in $12 \mathrm{ccm}$ physiol. Kochsalzlösung extrahiert.

Aussaat: Bouillonkultur von Bac. Typhi.

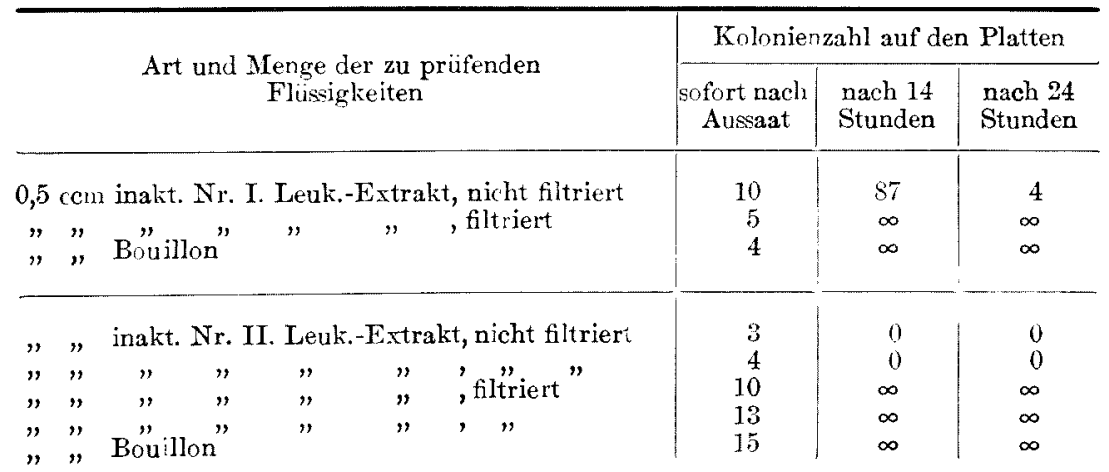


Tabelle XIV zeigt, dass die Kaninchenleukozy tenstoffe ihre Bakterizidie gegenüber Typhusbazillen durch Filtrieren mittels der Chamberla ndschen Kerze total verlieren.

\section{Versuch 12.}

Menschensera, die $\frac{1}{2}$ Stunde bei $56^{\circ} \mathrm{C}$ erhitzt waren, passierten den neuen sterilisierten $\mathrm{Ch}$ a m berland schen Filter.

\section{Tabelle XV.}

Menschensera: Nr. I; K.E., B, $25 \mathrm{Lj}$, Spitzenkatarrh.

Nr. II; K.N., 우, $41 \mathrm{Lj}$, Ulcus ventriculi.

Aussaat: Bouillonkultur von Bac. Typhi.

\begin{tabular}{|c|c|c|c|c|}
\hline & \multirow{2}{*}{$\begin{array}{l}\text { Art und Menge der zu priffenden } \\
\text { Fjissigkeiten }\end{array}$} & \multicolumn{3}{|c|}{ Kolonienzahl auf den Platten } \\
\hline & & $\begin{array}{c}\text { sofort nach } \\
\text { Aussaat }\end{array}$ & $\begin{array}{l}\text { nach } 14 \\
\text { Stunden }\end{array}$ & $\begin{array}{l}\text { nach } 24 \\
\text { Stunden }\end{array}$ \\
\hline $\begin{array}{l}0,5 \mathrm{ccn} \\
", " \\
", "\end{array}$ & $\begin{array}{l}\text { inakt. Nr. I. Serum, nicht filtriert } \\
\text { Bouillon }\end{array}$ & $\begin{array}{l}13 \\
15 \\
18\end{array}$ & $\begin{array}{l}37 \\
19 \\
\infty\end{array}$ & $\begin{array}{l}96 \\
14 \\
\infty\end{array}$ \\
\hline $\begin{array}{l}", \\
",\end{array}$ & $\begin{array}{l}\text { inakt. Nr. II. Serum, nicht filtriert } \\
\text { Bouillon } " \text {, filtriert }\end{array}$ & $\begin{array}{l}15 \\
11 \\
12\end{array}$ & $\begin{array}{r}2 \\
2 \\
\infty\end{array}$ & $\begin{array}{c}0 \\
0 \\
\infty\end{array}$ \\
\hline
\end{tabular}

Nach Filtrierung batten die Menschensera, wie Tabelle XV zeigt, ihre bakterizide Wirkung ohne Veränderung beibehalten.

\section{Versuch 13.}

\section{Tabelle XVI.}

Hundesera : Nr. I; Hund, $\delta$, braun, $5,5 \mathrm{~kg}$.

Nr. II; Hund, $q$, braun, $6,8 \mathrm{~kg}$.

Aussaat: Bouillonkultur ron Bac. Typhi.

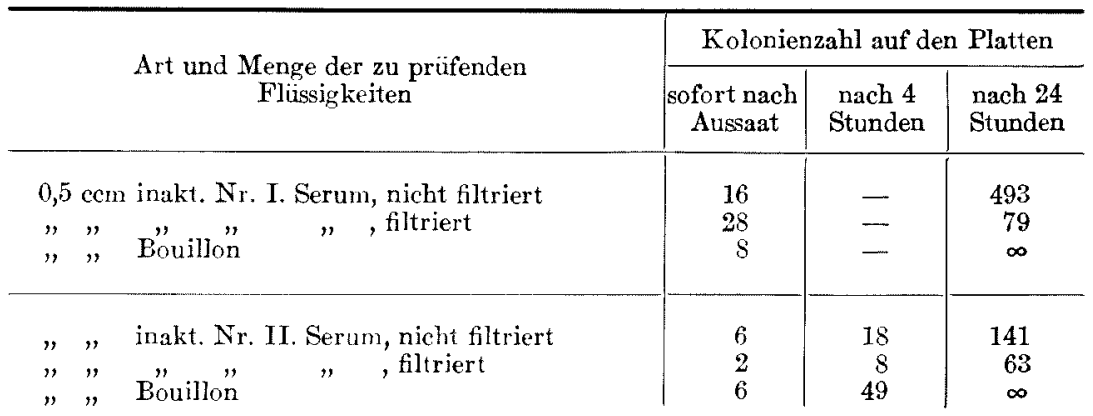


Die inaktiven Hundesera hatten auch durch Filtrieren ihre Wirkung nicht verloren (Tabelle XVI).

Unsere Resultate zeigen also, dass durch Filtrierung mittels der Chamber land schen Kerze die Lenkozytenstoffe ihre Wirkung verlieren, aber die thermostabilen Serumstoffe ihre Wirksamkeit noch unverändert besitzen. Wodurch dieser Unterschied zwischen den beiden Stoffen hervorgerufen wird, können wir dadurch erklären, dass dieselben Stoffe in verschiedenen Medien verschiedenes Verhalten zeigen. Eine analoge Erscheinung finden wir bei der Absorption des Ambozeptors durch Kaolin. Kaolin absorbiert aus dem unverdünnten Serum keinen Ambozeptor, während es ihn aus dem verdünnten stark absorbiert.

\section{E. Bakterizidie gegenüber verschiedenen Bakterienarten.}

Die bisher angeführten Untersuchungen wurden nur mit 'Typhusbazillen gemacht. Bei den folgenden Versuchen wurde die bakterizide Wirkung der Leukozytenstoffe und der Serumstoffe auf verschiedene Bakterienarten geprüft, und dafür wählten wir als Testbakterien ausser Typhusbazillen Bac. Paratyphi A, Bac. Paratyphi B, Bac. dysenteriae Shiga, Bac. dysenteriae Flexner, Bac. coli communis, Bac. diphtheriae, Bac. subtilis, Bac. anthracis, Staphylococcus aureus pyogenei, Streptococcus hämolyticus pyogenei und Pneumococcus aus.

Bei den Untersuchungen mit Strepto- und Pneumokokken wurde Blutagar und für die anderen Bakterien gewöhnliches Nähragar als Nährboden angewandt, welcher bei der bakteriziden Prüfung zum Plattengiessen benutzt werden muss.

Bei allen folgenden Versuchen wuchsen alle anderen geprüften Bakterjen, bloss abgesehen von Bac. diphtheriae, bei Kontrollversuchen nach 24 Stunden immer reichlich oder unendlich. Daher konnten wir ohne weiteres die bakterizide Krraft der zu prüfenden Flüssigkeiten je nach der gewachsenen Kolonienzahl auf den Platten richtig beurteilen. Aber nur die Diphtheriebazillen wuchsen bei Kontrollversuchen sehr ungleichmässig, bald gar nicht, bald reichlich, daher sind die mit diesen Bazillen geprütten Resultate unsicher. Aus diesem Grunde wurden die mit diesen Bazillen ausgeführten Versuche von den Tabellen ausgeschlossen.

\section{Kaninchenleukozytenextrakte.}

Aus den Berichten, die über die Bakterizidie der Kaninchenleuko- 


\section{Tabelle XVII.}

Nr. I : Kaninchen; $\hat{0}$, weiss, $1,86 \mathrm{~kg}$.

$0,35 \mathrm{~g}$ Leukozyten in $4,5 \mathrm{ccm}$ physiol. Kochsalzlösung extrahiert.

Nr. II : Kaninchen; o , weiss, $1,5 \mathrm{~kg}$.

$0,28 \mathrm{~g}$ Leukozyter in $4 \mathrm{ccm}$ physiol. Kochsalzlösung extrahiert.

Nr. III : Kaninchen; $q$, weiss, $1,6 \mathrm{~kg}$.

$0,31 \mathrm{~g}$ Leukozyten in $7 \mathrm{~cm}$ physiol. Kochsalzlösung extrahiert.

Nr. IV: Kaninchen; $\hat{o}$, braun, $1,65 \mathrm{~kg}$.

$0,5 \mathrm{~g}$ Leukozyten in $5,5 \mathrm{ccm}$ physiol. Kochsalzlösung extrahiert.

\begin{tabular}{|c|c|c|c|c|}
\hline \multirow[b]{2}{*}{ Testbakterien } & \multirow{2}{*}{$\begin{array}{l}\text { Nr. der zu prüfenden } \\
0,5 \text { cem inakt. Leuko- } \\
\text { zytenextrakte }\end{array}$} & \multicolumn{3}{|c|}{ Kolonienzahl auf den PJatten } \\
\hline & & $\begin{array}{c}\text { sofort nach } \\
\text { Aussaat }\end{array}$ & $\begin{array}{c}\text { nach } 4 \\
\text { Stunden }\end{array}$ & $\begin{array}{l}\text { nach } 24 \\
\text { Stunden }\end{array}$ \\
\hline Bac. Typhi & $\begin{array}{cc}\text { Nr. } & \text { I. } \\
n & \text { II. }\end{array}$ & $\begin{array}{r}2 \\
10\end{array}$ & $\begin{array}{l}0 \\
0\end{array}$ & $\begin{array}{l}0 \\
0\end{array}$ \\
\hline Bac. Paratyphi A & " $\quad$ III. & $\begin{array}{l}11 \\
11\end{array}$ & $\begin{array}{r}1 \\
39\end{array}$ & $\begin{array}{l}0 \\
0\end{array}$ \\
\hline Bac. Paratyphi B & " $\quad$ IV. & $\begin{array}{l}6 \\
5\end{array}$ & $\begin{array}{r}1092 \\
5\end{array}$ & $\begin{array}{l}\infty \\
\infty\end{array}$ \\
\hline $\begin{array}{l}\text { Bac. dysenteriae } \\
\text { Shiga }\end{array}$ & $" \quad$ II. & $\begin{array}{r}9 \\
17\end{array}$ & $\begin{array}{r}0 \\
13\end{array}$ & $\begin{array}{l}0 \\
5\end{array}$ \\
\hline $\begin{array}{c}\text { Bac. dysenteriae } \\
\text { Flexner }\end{array}$ & $\begin{array}{ll} & \text { III. } \\
& \text { IV. }\end{array}$ & $\begin{array}{r}8 \\
33\end{array}$ & $\begin{array}{l}9 \\
6\end{array}$ & $\begin{array}{l}0 \\
0\end{array}$ \\
\hline Bac. coli communis & $\begin{array}{l}n \\
" \quad \text { II }\end{array}$ & $\begin{array}{r}7 \\
17\end{array}$ & $\begin{array}{l}1 \\
3\end{array}$ & $\begin{array}{l}0 \\
0\end{array}$ \\
\hline Bac. subtilis & $" \quad$ II. & $\begin{array}{l}0 \\
3\end{array}$ & $\begin{array}{l}0 \\
0\end{array}$ & $\begin{array}{l}0 \\
0\end{array}$ \\
\hline Bac. anthracis & $\begin{array}{l}\text { III. } \\
\text { IV. }\end{array}$ & $\begin{array}{l}0 \\
2\end{array}$ & $\begin{array}{l}0 \\
0\end{array}$ & $\begin{array}{l}0 \\
0\end{array}$ \\
\hline $\begin{array}{l}\text { Staphylococ. } \\
\text { aureus pyogenei }\end{array}$ & $\begin{array}{ll}\text { " } & \text { II. } \\
" & \text { III. } \\
\text { IV. }\end{array}$ & $\begin{array}{r}10 \\
2 \\
26\end{array}$ & $\begin{array}{r}2 \\
4 \\
10\end{array}$ & $\begin{array}{r}40 \\
1 \\
162\end{array}$ \\
\hline $\begin{array}{l}\text { Streptococ. hïmolyt. } \\
\text { pyogenei }\end{array}$ & $\begin{array}{ll}\text { III. } \\
" \quad \text { IV. }\end{array}$ & $\begin{array}{l}1 \\
3\end{array}$ & $\begin{array}{l}2 \\
2\end{array}$ & $\begin{array}{r}80 \\
168\end{array}$ \\
\hline Pneumococcus & $\begin{array}{ll} & \text { III. } \\
& \text { IV. }\end{array}$ & $\begin{array}{r}0 \\
16\end{array}$ & $\begin{array}{r}0 \\
14\end{array}$ & $\begin{array}{r}0 \\
273\end{array}$ \\
\hline
\end{tabular}


zytenextrakte gegenüber verschiedenen Bakterienarten veröffentlicht worden sind, zitieren wir hier nur die folgenden, die das gleiche Versuchsmaterial benutzten wie wir: die Kaninchenleukozytenextrakte wirken bakterizid auf Typhusbazillen (Kling, ${ }^{4+1}$ Zinsser, ${ }^{21}$ Manwaring, ${ }^{2+4)}$ Schneider ${ }^{42}$ ), auf Heubazillen (Kling ${ }^{41}$ ), auf Milzbrandbazillen (Pettersson, ${ }^{305}$ Schneider, ${ }^{41)}$ Kling ${ }^{41}$ ), auf Staphylokokken (Zinsser, ${ }^{21)}$ Schneider ${ }^{41}$ ), auf Streptokokken (Pettersson,; ${ }^{; 2)} \mathbf{S}_{\mathrm{ch}}$ neider $\mathbf{r}^{41)}$ ) und auf Pneumokokken (Pettersson, ${ }^{32)}$ Schneider, ${ }^{41)}$ Dold $d^{48}$ ).

\section{Versuch 14.}

Die durch die Buchnersche Methode gewonnenen Kaninchenleukozytenextrakte wurden nach halbstündigem Erhitzen bei $56^{\circ} \mathrm{C}$ geprüft, weil die Kraft der Leukozytenstoffe mit den bereits alexinfreien thermostabilen Serumstoffen verglichen werden musste.

Nach Tabelle XVII können wir sagen, dass die Leukozytenstoffe auf Bac. Typhi, Bac. Paratyphi A, Bac. dysenteriae Shiga, Bac. dysenteriae Flexner, Bac. coli communis, Bac. subtilis u. Bac. anthracis bakterizid, auf Staphylococcus aureus pyogenei und Pneumococcus bald bakterizid, bald entwicklungshemmend, auf Streptococcus hämolyticus pyogenei nur entwicklungshemmend und auf Bac. Paratyphi B nicht abtötend wirken. Unsere Resultate zeigen also, dass ausser Bac. Paratyphi B alle anderen geprüften Bakterienarten mehr oder weniger von diesen Stoffen abgetötet werden, aber die Stärke dieser Kraft gegen einzelne Bakterienarten je nach den Leukozytenextrakten leicht schwankt.

\section{Kaninchensera.}

\section{Versuch 15 .}

Frische Kaninchensera wurden in aktivem und durch halbstündiges Erhitzen bei $56^{\circ} \mathrm{C}$ inaktiviertem Zustande bakterizider Prüfung unterzogen.

Sämtliche Resultate sind in Tabelle XVIII zusammengestellt.

Aktive Kaninchensera haben keine bakterizide Wirkung auf Staphylound Pneumokokken, aber auf die übrigen 9 Bakterienarten wirken sie bakterizid. Im Gegensatz zu den aktiven Sera wirken inaktive Sera abtötend nur auf Bac. dysenteriae Flexner, Bac. anthracis und Streptococcus, nicht aber auf die anderen Bakterienarten. 
Tabelle XVIII.

Kaninchenserum : aktiv und $\frac{1}{2}$ Stunde bei $56^{\circ} \mathrm{C}$ inaktiviert, $0,5 \mathrm{ccm}$ benutzt.

\begin{tabular}{|c|c|c|c|c|c|c|c|}
\hline \multirow{3}{*}{ Testbakterien } & \multirow{3}{*}{$\begin{array}{l}\text { Nr, und Art der } \\
\text { Kaninchen }\end{array}$} & \multicolumn{6}{|c|}{ Kolonienzahl auf den Platten } \\
\hline & & \multicolumn{2}{|c|}{$\begin{array}{l}\text { sofort nach } \\
\text { Aussaat }\end{array}$} & \multicolumn{2}{|c|}{$\begin{array}{l}\text { nach } 14 \\
\text { Stunden }\end{array}$} & \multicolumn{2}{|c|}{$\begin{array}{l}\text { nach } 24 \\
\text { Stunden }\end{array}$} \\
\hline & & aktiv & $\begin{array}{l}\text { in- } \\
\text { aktiv }\end{array}$ & aktiv & in- & aktiv & $\begin{array}{l}\text { in- } \\
\text { aktiv }\end{array}$ \\
\hline Bac. Paratyphi A & 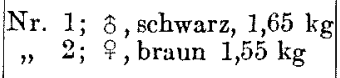 & $\begin{array}{l}7 \\
8\end{array}$ & $\begin{array}{l}14 \\
11\end{array}$ & $\begin{array}{l}1 \\
0\end{array}$ & $\begin{array}{r}\infty \\
258\end{array}$ & $\begin{array}{l}0 \\
0\end{array}$ & $\begin{array}{l}\infty \\
\infty\end{array}$ \\
\hline Bac. Paratyphi B & $\begin{array}{l}\text {, } 3 ; 0, \text { braun, } 1,6 \mathrm{~kg} \\
\Rightarrow \quad 4 ; \text { † weiss, } 1,5 \mathrm{~kg}\end{array}$ & $\begin{array}{l}16 \\
17\end{array}$ & $\begin{array}{l}24 \\
39\end{array}$ & $\begin{array}{r}10 \\
1\end{array}$ & $\begin{array}{l}\infty \\
\infty\end{array}$ & $\begin{array}{l}6 \\
0\end{array}$ & $\begin{array}{l}\infty \\
\infty\end{array}$ \\
\hline $\begin{array}{c}\text { Bac. dysenteriae } \\
\text { Shiga }\end{array}$ & $\begin{array}{l}\Rightarrow \quad 5 ; \delta, \text { braun, } 1,64 \mathrm{~kg} \\
" \quad 6 ; 0+\text { grau, } 1,67 \mathrm{~kg} \\
" \quad 7 ; \delta \text {, weiss, } 1,69 \mathrm{~kg}\end{array}$ & $\begin{array}{l}3 \\
3 \\
5\end{array}$ & $\begin{array}{l}3 \\
2 \\
4\end{array}$ & $\begin{array}{l}4 \\
1 \\
0\end{array}$ & $\begin{array}{c}\text { reichl. } \\
35 \\
\text { reichl. }\end{array}$ & $\begin{array}{l}3 \\
0 \\
0\end{array}$ & $\begin{array}{r}\infty \\
105 \\
\infty\end{array}$ \\
\hline $\begin{array}{l}\text { Bac. dysenteriae } \\
\text { Flexner }\end{array}$ & 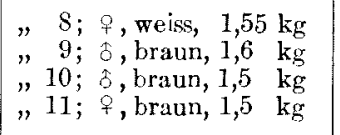 & $\begin{array}{r}11 \\
5 \\
- \\
-\end{array}$ & $\begin{array}{r}8 \\
2 \\
10 \\
5\end{array}$ & $\begin{array}{l}0 \\
0 \\
- \\
-\end{array}$ & $\begin{array}{l}5 \\
2 \\
2 \\
5\end{array}$ & $\begin{array}{r}0 \\
0 \\
- \\
-\end{array}$ & $\begin{array}{l}0 \\
0 \\
0 \\
9\end{array}$ \\
\hline Bac. coli communis & 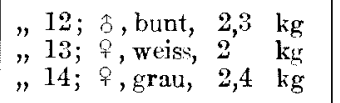 & $\begin{array}{r}6 \\
12 \\
4\end{array}$ & $\begin{array}{l}10 \\
11 \\
13\end{array}$ & $\begin{array}{l}0 \\
0 \\
0\end{array}$ & $\begin{array}{l}\infty \\
\infty \\
\infty\end{array}$ & $\begin{array}{l}0 \\
0 \\
0\end{array}$ & $\begin{array}{l}\infty \\
\infty \\
\infty\end{array}$ \\
\hline Bac. subtilis & $\begin{array}{l}\text { "15; } 9 \text {, schwarz, } 1,7 \mathrm{~kg} \\
\text { "16; of, braun, 1,75 kg } \\
\text { "17; } ; \text {, braun, } 2,9 \mathrm{~kg}\end{array}$ & $\begin{array}{r}0 \\
0 \\
-\end{array}$ & $\begin{array}{l}1 \\
2 \\
3\end{array}$ & $\begin{array}{l}2 \\
1 \\
-\end{array}$ & $\begin{array}{l}\infty \\
7 \\
0\end{array}$ & $\begin{array}{r}1 \\
0 \\
-\end{array}$ & $\begin{array}{l}\infty \\
\infty \\
\infty\end{array}$ \\
\hline Bac. anthracis & 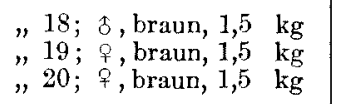 & $\begin{array}{r}0 \\
0 \\
-\end{array}$ & $\begin{array}{l}1 \\
1 \\
1\end{array}$ & $\begin{array}{l}0 \\
1 \\
-\end{array}$ & $\begin{array}{l}1 \\
0 \\
1\end{array}$ & $\begin{array}{r}3 \\
0 \\
-\end{array}$ & $\begin{array}{l}0 \\
0 \\
0\end{array}$ \\
\hline $\begin{array}{l}\text { Staphylococ. } \\
\text { aureus pyogenei }\end{array}$ & $\begin{array}{l}\text {,21; 字, bunt, } 1,35 \mathrm{~kg} \\
\text { "22; } \text {; bunt, } 1,8 \mathrm{~kg}\end{array}$ & $\begin{array}{l}10 \\
13\end{array}$ & $\begin{array}{l}19 \\
15\end{array}$ & $\begin{array}{l}\infty \\
\infty\end{array}$ & $\begin{array}{l}\infty \\
\infty\end{array}$ & $\begin{array}{l}\infty \\
\infty\end{array}$ & $\infty$ \\
\hline $\begin{array}{l}\text { Streptococ. hümo- } \\
\text { lyticus pyogenei }\end{array}$ & $\begin{array}{l}\text { "23; } 9, \text { braun, } 1,8 \mathrm{~kg} \\
\text { "24; } 8 \text {, braun, } 1,7 \mathrm{~kg} \\
\text { " 25; } 9 \text {, braun, 1,5 kg } \\
\text { "26; } 8 \text {, braun, 1,6 kg }\end{array}$ & $\begin{array}{r}3 \\
2 \\
- \\
-\end{array}$ & $\begin{array}{l}3 \\
1 \\
1 \\
2\end{array}$ & $\begin{array}{l}1 \\
5 \\
-\end{array}$ & $\begin{array}{r}7 \\
15 \\
0 \\
0\end{array}$ & $\begin{array}{r}0 \\
8 \\
-\end{array}$ & $\begin{array}{l}0 \\
0 \\
0 \\
0\end{array}$ \\
\hline Pneume & $\begin{array}{l}\text { „27; } 9 \text {, braun, } 1,6 \mathrm{~kg} \\
\text { "28; } \delta \text {, braun, 1,6 kg }\end{array}$ & $\begin{array}{l}6 \\
9\end{array}$ & $\begin{array}{r}11 \\
4\end{array}$ & $\begin{array}{l}50 \\
37\end{array}$ & $\infty$ & $\underset{\infty}{\text { reichl. }}$ & $\infty$ \\
\hline
\end{tabular}


Unsere Ergebnisse stimmen im allgemeinen mit denen anderer Forscher (Buchner, ${ }^{6)}$ Pettersson, ${ }^{30,32)}$ Kling, ${ }^{49}$ Dold, ${ }^{48)}$ Seiffert, ${ }^{49}$ Schou, ${ }^{597}$ Esch, $^{96}$ Selter ${ }^{53)}$ u.a.) überein, besonders wurde bestätigt, dass inaktive Kaninchensera bakterizid (Bon a du ce $\mathrm{e}^{4(6)}$ ) oder entwicklungshemmend (Pfeiler $\left.{ }^{56}\right)$ auf Bac. anthracis wirken. Seiffer $\mathrm{t}^{49}$ berichtet aber über die Bakterizidie der Sera gegen Streptococcus, dass sie höchstens nur gegen besondere Streptokokkenstämme entwicklungshemmend wirkten. Unseren Resultaten nach wirken sie bakterizid. Dieser Widerspruch liesse sich durch die Verschiedenheit der Stämme erklären.

Dass inaktive Kaninchensera auf Bac. dysenteriae Flexner abtötend wirken, wurde, soweit mir bekannt, bis jetzt noch nicht berichtet.

\section{Menschensera.}

\section{Versuch 16.}

Aktive und durch halbstündiges Erhitzen bei $56^{\circ} \mathrm{C}$ inaktivierte Krankensera wurden in frischem Zustande zur Prüfung der bakteriziden Wirkung auf verschiedene Bakterienarten benutzt.

Unsere Versuchsergebnisse sind in Tabelle XIX vermerkt.

Die geprüften 3 aktiven Sera haben alle bakterizide Kraft gegen 8 Bakterienarten, aber nicht gegen Staphylo-, Strepto- und Pneumokokken. Auf Streptokokken wirkt 1 Serum bakterizid und 2 Sera garnicht, aber auf Staphylo- und Pneumokokken wirken alle Sera garnicht bakterizid. Alle diese inaktiven Sera wirken bakterizid auf Bac. Typhi, Bac. Paratyphi A, Bac. dysenteriae Shiga, Bac. subtilis u. Bac. anthracis, aber auf Bac. dysenteriae Flexner wirken sie wachstumshemmend, auf Bac. Paratyphi B u. Bac. coli communis entwicklungshemmend oder nicht bakterizid, auf Streptococcus bakterizid oder garnicht und zuletzt auf Staphylo- n. Pneumococcus nicht bakterizid. Demnach wirken die aktiven Sera immer auf die geprüften Bakterien entweder bakterizid oder garnicht, nur abgesehen von Streptokokken, aber bei inaktiven Sera ist ihre Wirkung sehr verschieden, nicht nur je nach den Bakterienarten, sondern auch noch etwas schwankend je nach dem einzelnen Serum.

Mit den bereits veröffentlichten Resultaten der hier genannten Forscher (Dold, ${ }^{4+7}$ Seiffert, ${ }^{45}$ Schou, ${ }^{5,9}$ Selte ${ }^{53,5+1}$ ) stimmen unsere im allgemeinen überein, nur wirken nach den Selterschen Versuchen die inaktiven Sera bakterizid auf Staphylokokken, während unsere Ergebnisse sich mit den Seiffertschen decken und das Gegenteil zeigen. Weiter 


\section{Tabelle XIX.}

Menschen: Nr. I; S.S., $\delta, 54 \mathrm{Lj}$, Tabes dorsalis.

Nr. II; I.O., के, $28 \mathrm{Lj}$, Phthisis pulmonum.

Nr. III ; K.K., 今, 25 Lj., Myeloische Leukämie.

Menschenserum : aktiv und $\frac{1}{2}$ Stunde bei $56^{\circ} \mathrm{C}$ inaktiviert, $0,5 \mathrm{ccm}$ benutzt.

\begin{tabular}{|c|c|c|c|c|c|c|c|}
\hline \multirow{3}{*}{ Testbakterien } & \multirow{3}{*}{ Menschen-Nr. } & \multicolumn{6}{|c|}{ Kolonienzahl auf den Platten } \\
\hline & & \multicolumn{2}{|c|}{$\begin{array}{l}\text { sofort nach } \\
\text { Aussaat }\end{array}$} & \multicolumn{2}{|c|}{$\begin{array}{l}\text { nach } 14 \\
\text { Stunden }\end{array}$} & \multicolumn{2}{|c|}{$\begin{array}{l}\text { nach } 24 \\
\text { Stunden }\end{array}$} \\
\hline & & aktiv & $\begin{array}{c}\text { in- } \\
\text { aktiv }\end{array}$ & aktiv & \begin{tabular}{|c|} 
in- \\
aktiv
\end{tabular} & aktiv & $\begin{array}{c}\text { in- } \\
\text { aktir }\end{array}$ \\
\hline Bac. Typhj & $\begin{array}{cr}\text { Nr. } & \text { I. } \\
" & \text { II. } \\
" & \text { III. }\end{array}$ & $\begin{array}{r}2 \\
17 \\
22\end{array}$ & $\begin{array}{l}19 \\
15 \\
41\end{array}$ & $\begin{array}{l}3 \\
0 \\
2\end{array}$ & $\begin{array}{l}14 \\
36 \\
13\end{array}$ & $\begin{array}{l}0 \\
0 \\
0\end{array}$ & $\begin{array}{l}4 \\
3 \\
0\end{array}$ \\
\hline Bac. Paratyphi A & $\begin{array}{lr}" & \text { I. } \\
" & \text { II. } \\
& \text { III. }\end{array}$ & $\begin{array}{r}1 \\
18 \\
33\end{array}$ & $\begin{array}{r}18 \\
7 \\
27\end{array}$ & $\begin{array}{l}0 \\
0 \\
0\end{array}$ & $\begin{array}{r}13 \\
7 \\
38\end{array}$ & $\begin{array}{l}0 \\
0 \\
0\end{array}$ & $\begin{array}{r}5 \\
3 \\
14\end{array}$ \\
\hline Bac. Paratyphi B & $\begin{array}{rr}\text { " } & \text { I. } \\
\text { " } & \text { II. } \\
\text { " } & \text { III. }\end{array}$ & $\begin{array}{r}1 \\
4 \\
55\end{array}$ & $\begin{array}{l}16 \\
11 \\
70\end{array}$ & $\begin{array}{l}0 \\
0 \\
0\end{array}$ & $\begin{array}{c}125 \\
\text { reichl. } \\
328\end{array}$ & $\begin{array}{l}3 \\
1 \\
0\end{array}$ & $\begin{array}{c}313 \\
\infty \\
\text { reichl. }\end{array}$ \\
\hline $\begin{array}{l}\text { Bac. dysenteriae } \\
\text { Shiga }\end{array}$ & $\begin{array}{rr}" & \text { I. } \\
" & \text { II. } \\
" & \text { III. }\end{array}$ & $\begin{array}{r}0 \\
2 \\
11\end{array}$ & $\begin{array}{r}6 \\
2 \\
20\end{array}$ & $\begin{array}{l}0 \\
0 \\
0\end{array}$ & $\begin{array}{r}2 \\
7 \\
45\end{array}$ & $\begin{array}{l}0 \\
0 \\
0\end{array}$ & $\begin{array}{r}3 \\
5 \\
34\end{array}$ \\
\hline $\begin{array}{l}\text { Bac. dysenteriae } \\
\text { Flexner }\end{array}$ & $\begin{array}{rr}" & \text { I. } \\
" & \text { II. } \\
" & \text { III. }\end{array}$ & $\begin{array}{r}5 \\
12 \\
34\end{array}$ & $\begin{array}{r}2 \\
3 \\
39\end{array}$ & $\begin{array}{l}0 \\
0 \\
3\end{array}$ & $\begin{array}{r}0 \\
6 \\
44 \\
\end{array}$ & $\begin{array}{l}4 \\
0 \\
5\end{array}$ & $\begin{array}{r}5 \\
20 \\
63\end{array}$ \\
\hline Bac. coli communis & $\begin{array}{rr}" & \text { I. } \\
" & \text { II. } \\
" & \text { III. }\end{array}$ & $\begin{array}{r}0 \\
19 \\
17\end{array}$ & $\begin{array}{r}17 \\
3 \\
44\end{array}$ & $\begin{array}{l}0 \\
0 \\
0\end{array}$ & $\begin{array}{r}30 \\
2 \\
181\end{array}$ & $\begin{array}{l}0 \\
0 \\
0\end{array}$ & $\begin{array}{c}52 \\
\text { reichl. } \\
192\end{array}$ \\
\hline Bac. subtilis & $\begin{array}{rr}" & \text { I. } \\
" & \text { II. } \\
" & \text { III. }\end{array}$ & $\begin{array}{l}1 \\
2 \\
3\end{array}$ & $\begin{array}{l}1 \\
3 \\
4\end{array}$ & $\begin{array}{l}0 \\
0 \\
2\end{array}$ & $\begin{array}{l}0 \\
1 \\
0\end{array}$ & $\begin{array}{l}0 \\
0 \\
0\end{array}$ & $\begin{array}{l}0 \\
6 \\
0\end{array}$ \\
\hline Bac. anthracis & $\begin{array}{rr}" & \text { I. } \\
" & \text { II. } \\
" & \text { III. }\end{array}$ & $\begin{array}{l}1 \\
0 \\
1\end{array}$ & $\begin{array}{l}1 \\
0 \\
1\end{array}$ & $\begin{array}{l}0 \\
0 \\
0\end{array}$ & $\begin{array}{l}0 \\
0 \\
3\end{array}$ & $\begin{array}{l}0 \\
0 \\
0\end{array}$ & $\begin{array}{l}0 \\
0 \\
0\end{array}$ \\
\hline $\begin{array}{l}\text { Staphylococ. } \\
\text { aureus pyogenei }\end{array}$ & $\begin{array}{lr}" & \text { I. } \\
" & \text { II. } \\
" & \text { III. }\end{array}$ & $\begin{array}{l}35 \\
45 \\
22\end{array}$ & $\begin{array}{r}34 \\
3 \\
24\end{array}$ & $\begin{array}{l}3 \\
\infty \\
\infty\end{array}$ & $\begin{array}{c}\text { reichl. } \\
\text { reichl. } \\
\infty\end{array}$ & $\begin{array}{c}\text { reichl. } \\
\infty \\
\infty\end{array}$ & $\begin{array}{l}\infty \\
\infty \\
\infty\end{array}$ \\
\hline $\begin{array}{l}\text { Streptococ. hämolyt. } \\
\text { pyogenei }\end{array}$ & $\begin{array}{rr}" & \text { I. } \\
" & \text { II. } \\
" & \text { III. }\end{array}$ & $\begin{array}{l}2 \\
3 \\
2\end{array}$ & $\begin{array}{l}1 \\
2 \\
1\end{array}$ & $\begin{array}{c}36 \\
7 \\
\text { reichl. }\end{array}$ & $\begin{array}{c}58 \\
6 \\
\text { reichl. }\end{array}$ & $\begin{array}{c}\infty \\
0 \\
\infty\end{array}$ & $\begin{array}{c}\infty \\
1 \\
\text { reichl. }\end{array}$ \\
\hline Pneumococcus & $\begin{array}{rr} & \text { I. } \\
" & \text { III. } \\
& \text { III. }\end{array}$ & $\begin{array}{r}7 \\
11 \\
10\end{array}$ & $\begin{array}{r}3 \\
4 \\
11\end{array}$ & $\begin{array}{c}\text { reichl. } \\
34 \\
13\end{array}$ & $\begin{array}{c}\text { reichl. } \\
\text { reichl. } \\
\infty\end{array}$ & $\begin{array}{l}\infty \\
\infty \\
\infty\end{array}$ & $\begin{array}{l}\infty \\
\infty \\
\infty\end{array}$ \\
\hline
\end{tabular}


können wir die Frage entscheiden, ob diese thermostabilen menschlichen Serumstoffe durch Leukozy tose hervorrufende Krankheiten sich vermehren oder nicht, weil das Serum Nr. III in Tabelle XIX einem an myeloischer Leukämie Erkrankten entnommen wurde und dabei die Leukozytenanzahl in seinem Blute 139,400 in $1 \mathrm{cmm}$ betrug. Wie die Tabelle zeigt, findet im Vergleich mit anderen Fällen keine Vermehrung der Stoffe bei diesem Falle statt. Daraus geht hervor, dass diese Stoffe sich nicht durch Leukozytose vermehren, sondern dass ihre Vermehrung durch etwaige Reize hervorgerufen wird, die auf Leukozyten wirken, wie z.B. die Doldschen Fälle, bei denen sich die thermostabilen bakteriziden Stoffe gegenüber virulenten Pneumokokken beim akuten fieberhaften Zustande im Blute vermehrten.

Wenn wir die Wirksamkeit zwischen Kaninchenleukozy tenstoffen und inaktiven Kaninchenserumstoffen vergleichen, wirken erstere nicht nur auf alle Bakterienarten, die durch letztere abgetötet werden, sondern noch auf andere Bakterienarten, welche durch letztere nicht angegriffen werden.

Über die bakterizide Kraft der menschlichen Leukozytenextrakte berichtete Rubritius, ${ }^{2.2}$ dass die von menschlichen tuberkulösen Senkungsabszessen gewonnenen Leukozyten, welche in verschiedenen Flüssigkeiten aufgeschwemmt worden waren, starke bakterizide Wirkung auf Milzbrandbazillen und avirulente Staphylo- und Streptokokken haben.

Selter ${ }^{5-j)}$ der auch Leukozyten von menschlichen Abszesseitern gewann, bestätigte, dass die aus diesen Jeukozyten extrahierten Stoffe auf Typhus-, Paratyphus-B-, Coli-, Dysenterie- und Pseudodysenteriebazillen bakterizid wirken und dass diese Stoffe thermastabil sind.

Danach kann man sagen, dass die menschlichen Leukozyten auch bakterizide Stoffe gegenüber verschiedenen Bakterienarten abgeben und diese zum Teile im Serum gefunden werden.

\section{F. Zeitverlauf der Bakterizidie.}

Früher, im I. Kapitel, berührten wir kurz den zeitlichen Unterschied der bakteriziden Wirkung zwischen Serumalexinen und thermostabilen Serumstoffen, und damals nahmen wir an, dass, während bei aktiven Sera ihre Bakterizidie gegen Typhusbazillen in der Regel schon nach 4 Stunden erzielt wird, bei inaktiven Sera die eingesäten Bazillen nach 4 oder 14 Stunden noch nicht abgetötet sind, sondern sich vielmehr etwas vermehren und erst nach 24 Stunden vernichtet werden.

Nun betrachten wir weiter, ob dieser Unterschied ausser bei Typhus- 
bazillen noch bei anderen Bakterien gefunden werden kann, und ferner wollen wir den zeitlichen Verlauf der keimtötenden Kraft der Leukozytenextrakte kennen lernen.

\section{Kaninchensera.}

Da inaktive Kaninchensera nur auf Bac. dysenteriae Flexner, Bac. anthracis und Streptococcus bakterizid wirken (Tabelle XVIII), so können wir den obengenannten Unterschied nur bei diesen 3 Bakterienarten beobachten. Die Milzbrandbazillen werden sowohl durch aktive wie auch inaktive Sera schon nach 14 Stunden abgetötet, während Streptokokken und Flexnersche Dysenteriebazillen erst nach 24 Stunden vernichtet werden, wobei es auffallend ist, dass sie sich in manchen Fällen nach 14 Stunden eher etwas vermehren.

\section{Menschensera.}

Inaktive Menschensera wirken, wie Tabelle XIX zeigt, ausser auf Typhusbazillen, auf Bac. Paratyphi A, Bac. dysenteriae Shiga, Bac. subtilis und Bac. anthracis bakterizid, und bei den ersten 2 Bakterienarten findet sich obengenannter Unterschied in der Tat, aber die 2 letzteren Bakterienarten werden durch aktive und inaktive Sera innerhalb 14 Stunden abgetötet.

\section{Leukozytenextrakte.}

Durch Leukozytenextrakte werden Typhusbazillen (Tabelle V, VII, X, XII, XIV u. XVII), Bac. Paratyphi A und Bac. dysenteriae Flexner (Tabelle XVII) nach 4 Stunden je nach den Extrakten bald rasch, bald langsam abgetötet, aber Bac. dysenteriae Shiga, Bac. coli, Bac. subtilis und Bac. anthracis (Tabelle XVII) werden immer rasch in gleich langer Zeit abgetötet. UUber Staphylo- und Pneumokokken können wir nichts Sicheres sagen.

Betreffs der langsam wirkenden Eigenschaft der Leukozytenextrakte behauptet Pettersson ${ }^{39}$ dass diese langsamere Wirkung der Leukozytenstoffe im Vergleich mit Serumalexinen das eigentliche Unterscheidungsmerkmal zwischen beiden Stoffen ist, aber Schneider ${ }^{42}$ nahm dies nicht an, sondern glaubte, dass diese Wirkung nur auf einer geringeren keimtötenden Kraft der Leukozytenextrakte Petterssons beruht. Weil ${ }^{203}$ erkannte auch die Petterssonsche Behauptung nicht an und meinte, dass 
dies sicherlich nur ausnahmsweise zutrifft. Wir können durch unsere Versuche mit Sicherheit annehmen, dass sowohl inaktive Sera als anch Leukozytenextrakte auf einige Bakterienarten langsamer als Serumalexine wirken; da diese Stoffe in den Sera in geringer und relativ bestimmter Menge enthalten sind, so ist diese Erscheinung bei inaktiven Sera konstant sichtbar, doch bei Leukozytenextrakten kommt diese langsame Wirkung auf eine bestimmte Bakterienart je nach den Extraktarten nicht immer zum Vorschein, da ihre Menge sehr variabel ist. Darnach kann man sagen, dass diese Erscheinung nur dann zustande kommt, wenn diese Stoffe in relativ geringer Menge vorhanden sind. Deshalb darf man überhaupt bei Ausführung der bakteriziden Prüfung thermostabiler Serumstoffe oder Leukozytenstoffe nicht vergessen, die Prüfung nach 24 Stunden wiederum anzustellen, denn sonst kann man nicht mit Sicherheit ihre Bakterizidie bestimmen.

Durch die bisher ausgeführten vergleichenden Untersuchungen zwischen thermostabilen Serumstoffen und Leukozytenstoffen sehen wir, dass diese beiden Stoffe gemeinsame Eigenschaften haben und wahrscheinlich identisch sind. Aber die Frage, ob diese Serumstoffe von den lebenden Leukozyten ins Blut abgegeben werden oder beim Zerfall der Leukozyten frei werden, können wir nicht sicher entscheiden.

Die Frage, was diese Stoffe sind, können wir hier auch nicht beantworten, aber wir vermuten, dass es sich wahrscheinlich um einen fermentartigen Körper handelt.

Zum Schlusse müssen wir betonen, dass ausser Opsonin und Alexin bakterizide Stoffe, die von Leukozyten abstammen, sicherlich in normalen Sera von Menschen und gewissen Tierarten vorhanden sind und diese auch als Schutzapparat des Organismus gegen verschiedene Bakterienarten eine Rolle spielen.

\section{Sind thermostabile bakterizide Stoffe in besonderen Organen auffallend zahlreich enthalten?}

Aus der Erkenntnis, dass die thermostabilen bakteriziden Serumstoffe aus Leukozyten abstammen, erhebt sich natürlich die Frage, ob diese Stoffe in hämatopoetischen Organen in besonders grosser Menge gefunden werden. Früher bestätigte $\mathrm{Han} \mathrm{k} \mathrm{in}{ }^{57)}$ dass der von Rattenmilz durch eine bestimmte Methode gewonnene Eiweisskörper Milzbrandbazillen vernichtende Kraft besitzt und dass diese Kraft durch Kochen völlig zerstört wird. 
Aber nach der Petterssonschen Arbeit ${ }^{i 0)}$ wirken die durch die Buchnersche Methode erhaltenen Bouillonextrakte von Milz oder Knochenmark der mit Milzbrandbazillen immunisierten Kaninchen und Ziegen nicht bakterizid auf Milzbrandbazillen. Über diese Frage wurden folgende Untersuchungen angestellt.

\section{Versuch 17.}

1. Zuerst wurden Presssäfte aus verschiedenen Organen von Kaninchen und Hund zur bakteriziden Prüfung gegenüber Typhusbazillen hergestellt. Kaninchen oder Hund wurde aus Karotis verblutet, und darauf wurden ihnen verschiedene Organe möglichst aseptisch entnommen. Ejnzelne Organe wurden unter Zusatz einiger ccm physiologischer Kochsalzlösung möglichst zerkleinert und dann aus dieser Masse die Organsäfte mittels Presse herausgedrückt.

Die so gewonnenen Organsäfte wurden durch starke Zentrifugierung von Gewebsfetzen befreit. Diese Säfte wurden dann, je $1 \mathrm{ccm}$, in kleine Glasröhrchen abpipettiert und nach halbstündigem Erhitzen bei $56^{\circ} \mathrm{C}$ zur Prüfung benutzt.

\section{Tabelle XX.}

Nr. I : Kaninchen; †, weiss, $1,65 \mathrm{~kg}$.

Nr. II: Hund; $q$, schwarz, $13 \mathrm{~kg}$.

Aussaat: Bouillonkultur von Bac. Typhi.

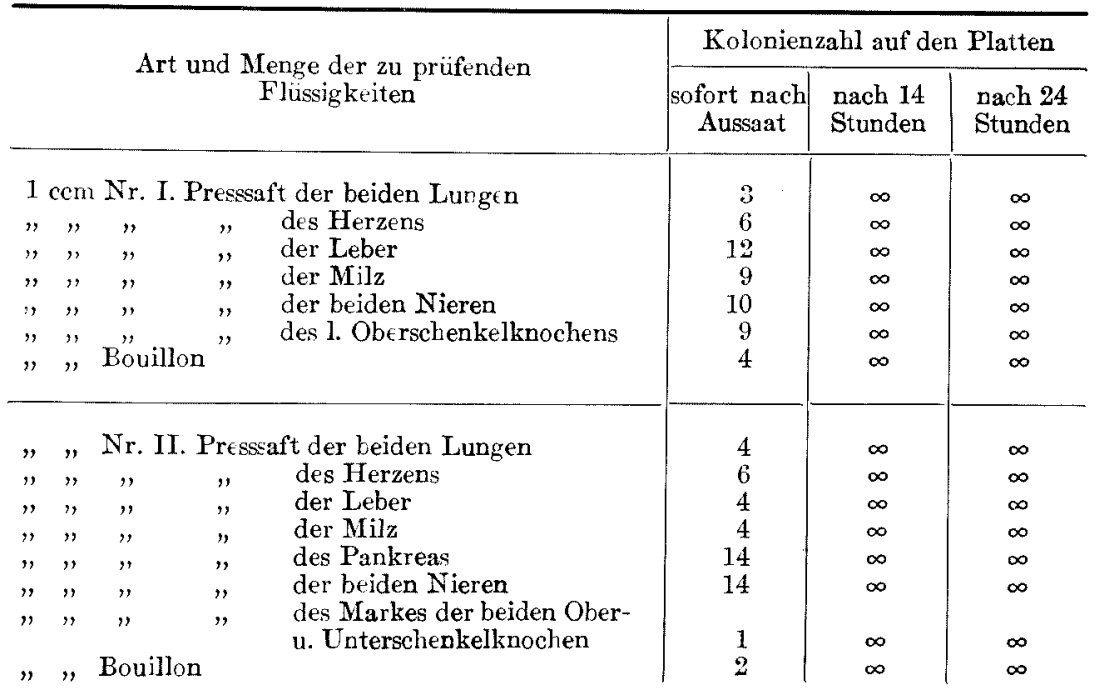


Tabelle XX zeigt, dass alle Presssäfte der verschiedenen Organe von Kaninchen und Hund obne Ausnahme keine bakterizide Wirkung gegenüber Typhusbazillen haben.

2. Dann wurden die durch obige Methode gewonnenen Presssäfte durch dieselbe Extraktionsmethode wie die bei der Gewinnung von Leukozytenextrakten extrahiert und diese Extrakte nach halbstündigem Erhitzen bei $56^{\circ} \mathrm{C}$ geprüft.

\section{Tabelle XXI.}

Nr. I: Kaninchen : $\hat{\delta}$, bunt, $1,43 \mathrm{~kg}$.

Nr. II : Hund; $\hat{o} 12 \mathrm{~kg}$.

Aussaat: Bouillonkultur von Bac. Typhi.

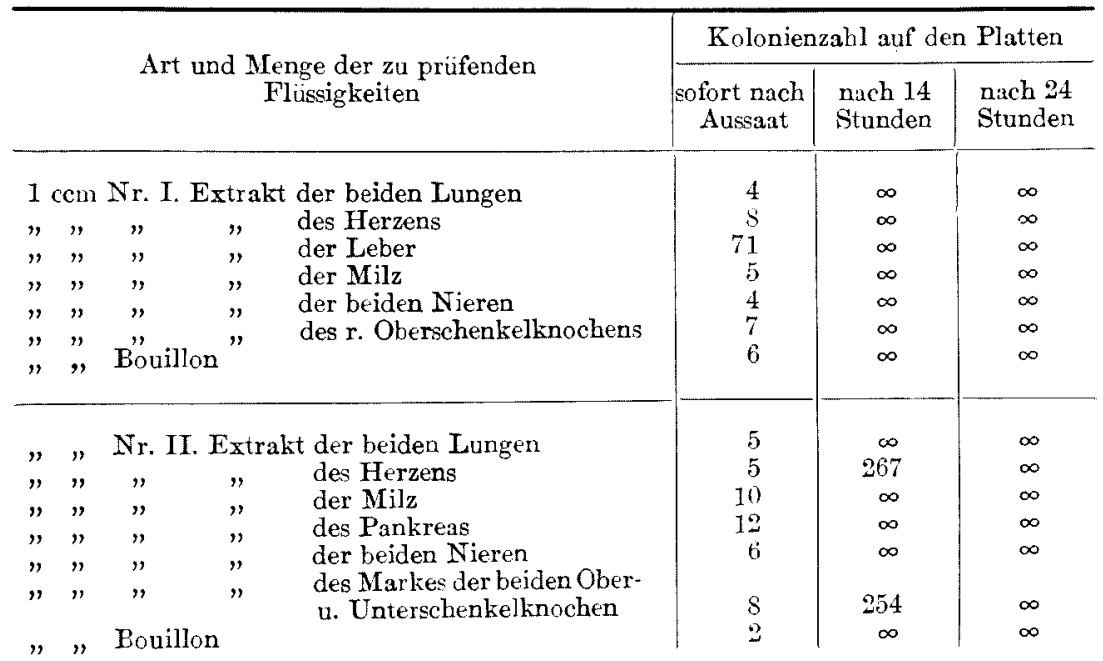

Aber wie Tabelle XXI zeigt, haben sämtliche Extrakte von Kaninchen und Hunden keine Typhusbazillen vernichtende Kraft. Unsere Ergebnisse blieben immer negativ. Ob daran die Methode schuld ist oder ob die Organe in der Tat keine bakterizide Stoffe als solche enthalten, können wir vorläufig noch nicht entscheiden.

\section{Zusammenfassung.}

1. Die thermostabilen bakteriziden Serumstoffe gegenüber Typhusbazillen sind bei Menschen konstant vorhanden, aber bei Tieren werden sie nur in bestimmten Tieren gefunden, d.h. von den geprüften Tieren, Schweinen, Hunden, Pferden, Hammeln, Kaninchen, Meerschweinchen 
und Rindern, haben nur Schweine und Hunde dauernd diese Stoffe in ihren Sera, die anderen Tiere haben sie nur vorübergehend oder sehr schwach oder garnicht.

2. Diese Serumstoffe haben keine Beziehung zur natürlichen oder künstlich erzeugten Immunität. Wenn sie auch in einem Tier gegen eine Bakterienart bakterizid wirken, so spricht das doch noch nicht dafür, dass das entsprechende Tier für diese Bakterienart empfänglich ist, was Seiffert einst behauptet hat. Und diese Stoffe bleiben auch nach künstlicher Immunisierung ohne Veränderung.

3. Folgende Eigenschaften besitzen Serumstoffe und bakterizide Leukozytenstoffe gemeinsam.

a. Beide Stoffe sind thermostabil.

b. Beide Stoffe behalten ihre Bakterizidie nach langdanerndem Aufenthalt im Eisschrank ohne Veränderung.

c. Beide Stoffe werden nicht mittels Äthers extrahiert, sondern bleiben unverändert im Rückstand.

d. Alle durch thermostabile Serumstoffe abgetötete Bakterien werden immer auch von Leukozytenstoffen vernichtet.

e. Eine langsamere bakterizide Wirkung von Serum- und Leukozytenstoffen im Vergleich mit Serumalexinen ist sicherlich vorhanden, wenn diese Stoffe mit geeigneten Bakterien und in nicht zu grosser Menge geprüft werden.

f. Die Serumstoffe passieren durch die Ch a mber land sche Kerze, aber die Leukozytenstoffe sind nicht filtrierbar. Diese Differenz zeigt nicht die Verschiedenheit der beiden Stoffe, sondern wird durch die Verschiedenheit der Medien, in denen sich die beiden Stoffe befinden, hervorgerufen.

Also sind bakterizide Serumstoffe und Leukozytenstoffe höchstwahrscheinlich identisch.

4. Diese thermostabilen bakteriziden Stoffe können in Organen nicht nachgewiesen werden. 


\section{Literatur.}

(1) Fod or, Deut. med. Wochenschr., 1887, 13, 745.

(2) Nuttall, Zeitsch. f. Hyg., 1888, 4, 352.

(3) Behring, Centralbl. f. klin. Med., 1888, 9, 681.

(4) Buchner, Centralbl. f. Bakt. u. Parasit, 1889, 5, 817.

(5) Derselbe, ebenda, $1889,6,1$ u. 561.

(6) Derselbe, Arch. f. Hyg., 1890, 10, 84.

(7) Hahn, Arch. f. Hyg., 1895, 25, 105.

(8) Schattenfroh, Arch. f. Hyg., 1897, 31, 1.

(9) Derselbe, Münch. med. Wochenschr., 1897, 44, 4.

(10) Derselbe, ebenda, 1897, 44, 414.

(11) Derselbe, Arch. f. Hyg., 1899, 35, 135.

(12) Dii u bler, Centralbl. f. Bakt. u. Paras., 1899, 25, 129.

(13) Gruber, Münch. med. Wochenschr., 1901, 48, 1965.

(14) Lambot te u. Stiennen, Centralbl. f. Bakt. u. Paras., 1906, 40, 1224.

(15) Gruber u. Futaki, Münch. med. Wochenschr., 1907, 54, 249.

(16) Korschun, Ann. de l' Inst. Pasteur. 1908, 22, 586.

(17) Werbitzki, Arch. f. Hyg., 1909, 70, 299.

(18) Weil, Arch. f. Hyg., 1909, 71, 223.

(19) Weil u. N unok aw a, Centralbl. f. Bakt. u. Paras., 1910, 54, 262.

(20) Weil, Arch.f. Hyg., 1911, 74, 289.

(21) Zinsser, Journ. of Med. Res., 1910, 22, 397.

(22) Rubritius, Beitr. z. klin. Chir., 1910, 66, 337.

(23) Derselbe, Arch. f. Hyg., 1911, 74, 211.

(24) Manwaring, Journ. of Exp. Med., 1912, 16, 249.

(25) Derselbe, ebenda, 1913, 17, 409.

(26) Esch, Zeitschr. f. Hyg., 1914, 77, 389.

(27) Pettersson, Centralbl. f. Bakt. u. Paras., 1905, 39, 423.

(28) Derselbe, ebenda, 1906, 40, 587.

(29) Derselbe, ebenda, 1906, 42, 56.

(30) Derselbe, Zeitschr. f. klin. Med, 1907, 63, 79.

(31) Derselbe, Centralbl. f. Bakt. u. Paras., 1908, 45, 160.

(32) Derselbe, ebenda, 1908, 45, 235.

(33) Derselbe, ebenda, 1908, 46, 405.

(34) Derselbe, Zeitschr. f. Inmunitätsf., 1909, 1, 52.

(35) Derselbe, Centralbl. f. Bakt. u. Paras., 1909, 50, 634.

(36) Derselbe, ebenda, 1910, 154, 131.

(37) Derselbe, Zeitschr. f. Immunitiitsf, 1910, 7, 693.

(38) Derselbe, Centralbl. f. Bakt. u. Paras., 1911. 60, 286.

(39) Derselbe, Zeitschr. f. Immunitätsf., 1917, 26, 305.

(40) Schneider, Münch med. Wochenschr., 1908, 55, 499.

(41) Derselbe, Arch. f. Hyg., 1909, 70, 40.

(42) Derselbe, ebenda, 1912, 75, 167.

(43) Schneider u. Hurler, Arch. f. Hyg., 1913, 81, 372.

(44) K l ing, Zeitschr. f. Immunitütsf., 1910, 7, 1.

(45) Behring u. Nissen, Zeitschr. f. Hyg., 1890, 8, 412. 
(46) Bonaduce, Zieglers Beitr. z. pathol. Anat. etc. 1893, 12, 353.

(47) Pirenne, Centralbl. f. Bakt. u. Paras., 1904, 36, 256.

(48) Dold, Arbeiten a. d. kaiserl. Gesundheitsa., 1911, 39, 419.

(49) Seiffert, Deut. med. Wochenschr., 1912, 38, 305.

(50) Derselbe, ebenda, 1912, 38, 2059.

(51) Derselbe, ebenda, 1917, 43, 362 .

(52) Schou, Zeitschr. f. Hyg., 1913, 75, 539.

(53) Selter, Zeitschr. f. Hyg., 1918, 86, 313.

(54) Derselbe, Zeitschr. f. Immunitätsf., 1920, 30, 105.

(55) Pettersson, Zeitschr f. Immunitätsf, 1924, 40, 43.

(56) Pfeiler, Arch. f. Hyg., 1922, 91, 217.

(57) H ankin, Centralbl. f. Bakt. u. Paras., 1891, 9, 336 u. 372. 